\title{
Transition-Metal-Catalyzed Regioselective Arylation and Vinylation of Carboxylic Acids
}

\author{
Tetsuya Satoh and Masahiro Miura
}

\begin{tabular}{|c|l|}
\hline Citation & Synthesis 2010(20): 3395-3409 \\
\hline Issue Date & $2010-8-25$ \\
\hline Type & Journal Article \\
\hline Textversion & author \\
\hline Rights & $\begin{array}{l}\text { This is an Accepted Manuscript of an article published by Thieme Publishing Group } \\
\text { in Synthesis on 2010, available online at https://doi.org/10.1055/s-0030-1258225. } \\
\text { This is not the published version. Please cite only the published version. } \\
\text { この論文は出版社版でありません。引用は出版社版をご利用ください。 }\end{array}$ \\
\hline DOI & \begin{tabular}{l}
$10.1055 / \mathrm{s}-0030-1258225$ \\
\hline
\end{tabular} \\
\hline
\end{tabular}

\author{
Self-Archiving by Author(s) \\ Placed on: Osaka City University
}




\title{
Transition-Metal-Catalyzed Regioselective Arylation and Vinylation of Car- boxylic Acids
}

\author{
Tetsuya Satoh* and Masahiro Miura* \\ Department of Applied Chemistry, Faculty of Engineering, Osaka University, Suita, Osaka 565-0871, Japan \\ Fax +81(6)68797362; E-mail: satoh@chem.eng.osaka-u.ac.jp; miura@ chem.eng.osaka-u.ac.jp \\ Received
}

Abstract: Arene and heteroarene carboxylic acids undergo regioselective arylation and vinylation reactions at the ortho- (cine-) and ipso-positions of their carboxyl function under transition-metal catalysis accompanied by $\mathrm{C}-\mathrm{H}$ and $\mathrm{C}-\mathrm{C}$ bond cleavages, respectively. The recent progress of the directed reactions is summarized in this article.

$\begin{array}{ll}1 & \text { Introduction } \\ 2 & \text { ortho- (cine-) Arylation } \\ 3 & \text { ortho- (cine-) Vinylation } \\ 4 & \text { ipso-Arylation } \\ 5 & \text { ipso-Vinylation } \\ 6 & \text { Conclusions }\end{array}$

Key words: carboxylic acids, arylation, olefination, $\mathrm{C}-\mathrm{H}$ bond cleavage, decarboxylation

\section{$1 \quad$ Introduction}

The transition-metal-catalyzed $\mathrm{C}-\mathrm{C}$ bond formation reactions via $\mathrm{C}-\mathrm{H}^{1}$ and $\mathrm{C}-\mathrm{C}^{2}$ bond cleavages have attracted much attention from the atom- and stepeconomical and chemoselective points of view. So far, a variety of catalytic processes involving different modes to activate the relatively inert bonds have been developed. Among the most promising activation strategies is to utilize the proximate effect by coordination of a functional group in a given substrate to the metal center of a catalyst, which enables regioselective functionalization.

As pioneering work in this area, Murai and co-workers reported the ruthenium-catalyzed ortho-alkylation of aromatic ketones with alkenes. ${ }^{3}$ Since the breakthrough, not only alkylation but also arylation and vinylation have been developed, which are recognized to be powerful tools to precisely construct $\pi$-conjugated molecules. As such examples, we reported the ortho- and ipso-arylation reactions of tert-benzyl alcohols under palladium catalysis (Scheme 1). ${ }^{4-8}$

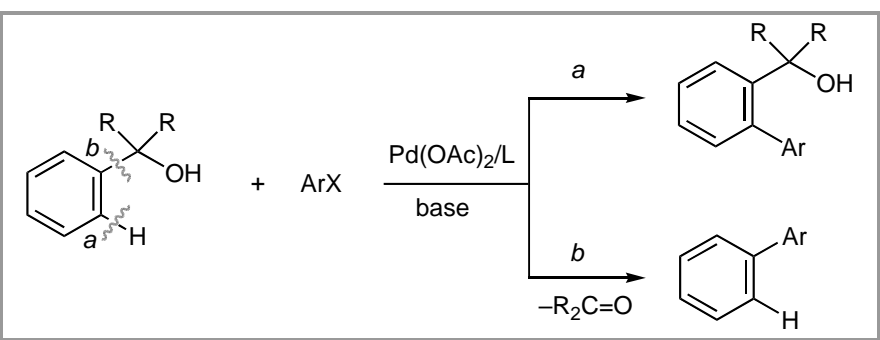

Scheme 1

These reactions proceed via (1) oxidative addition of aryl halide $(\mathrm{ArX})$ to $\mathrm{Pd}^{0}$ generated in situ to give an arylpal- ladium species $(\operatorname{ArPdX})$ and $(2)$ coordination of the alcoholic oxygen to the palladium center to form an arylpalladium alkoxide as a key intermediate (Scheme 2). Depending on the reaction conditions, the intermediate selectively undergoes cyclopalladation to produce an ortho-arylated product (step (3), path $a$ ) or $\beta$-carbon elimination to yield an ipso-arylated product with the release of a ketone (path $b$ ).

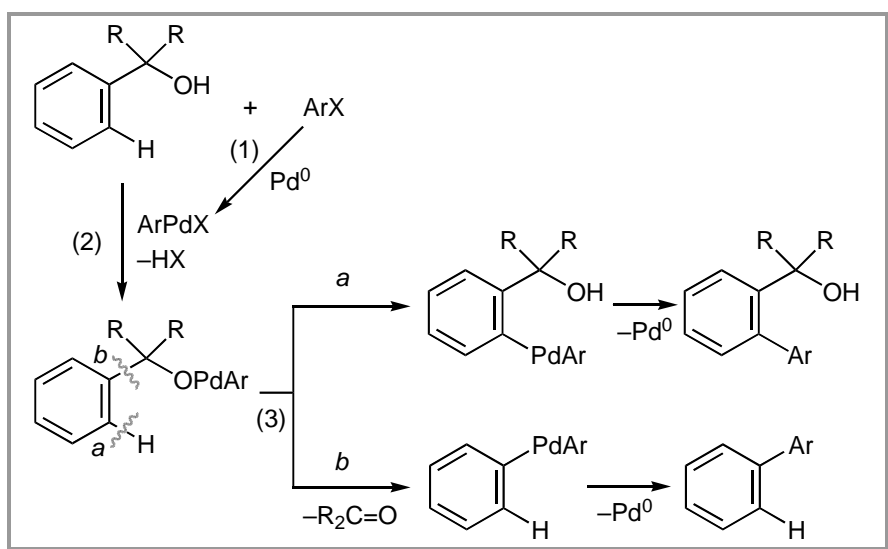

Scheme 2

The vinylation reactions of tert-propargyl alcohols by oxidative coupling with alkenes under palladium catalysis ${ }^{9}$ and by homocoupling under rhodium catalysis, ${ }^{10,11}$ which involve a similar $\beta$-carbon elimination process to that in Scheme 2, have also been developed as the synthetic methods of enyne derivatives (Scheme 3 ). Thus, the hydroxymethyl group effectively acts as leaving group as well as directing group.

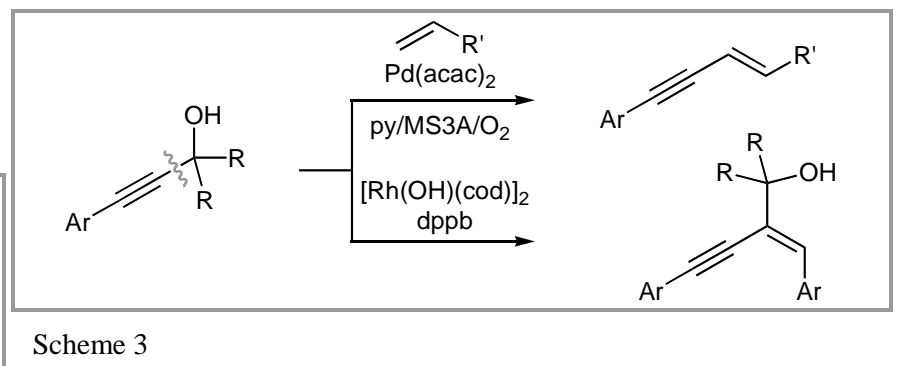

On the other hand, a carboxyl group is also known to act as a good anchor to bring about the directed substitution. The stoichiometric reactions of transition-metal complexes with benzoic and acrylic acids involving the directed $\mathrm{C}-\mathrm{H}$ bond cleavages were reported (Scheme 4). ${ }^{12,13}$ Larock and co-workers also disclosed the stoichi- 
ometric ortho-vinylation of benzoic acid via orthothallation, transmetalation, and alkene insertion (Scheme 5). ${ }^{14}$

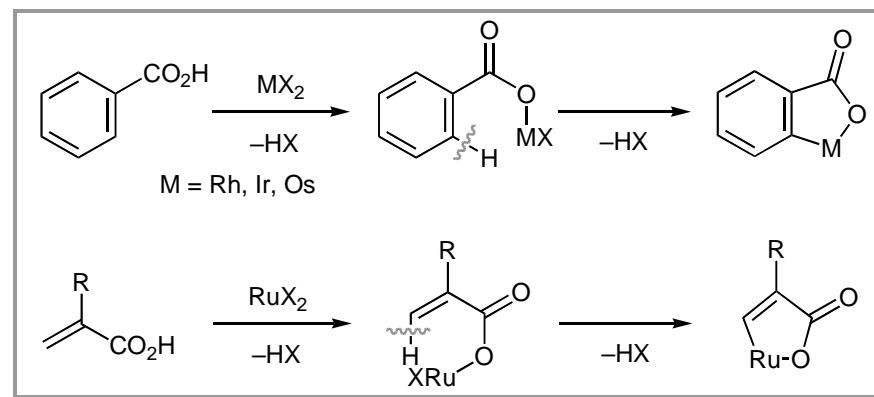

Scheme 4

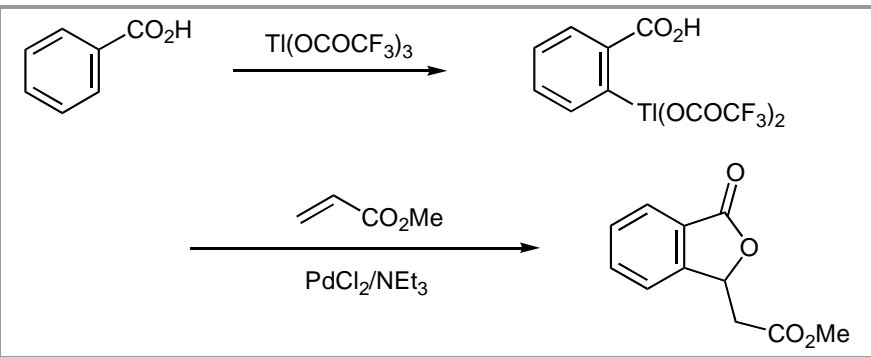

Scheme 5

In 1998, we succeeded in conducting this transformation catalytically by using a $\mathrm{Pd} / \mathrm{Cu}$ catalyst system under air (Scheme 6). ${ }^{15}$ Then, as shown in Scheme 7, not only ortho- (cine-) functionalization (path a) but also ipsoarylation $^{16,17}$ and vinylation reactions accompanied by decarboxylation (path $b$ ) have been developed. The reactions of carboxylic acids appear to be synthetically more important because of their wide availability as building blocks. In this review, recent examples of such regioselective arylation and vinylation reactions directed by the key substituent are presented.

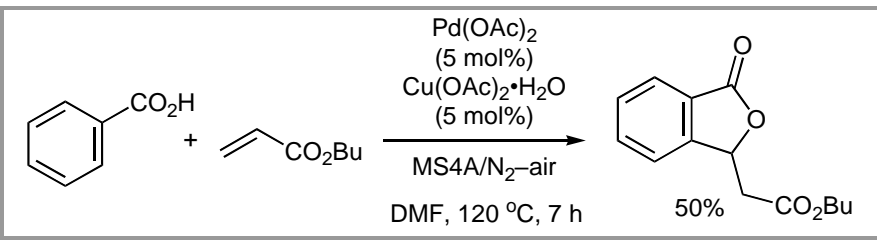

Scheme 6

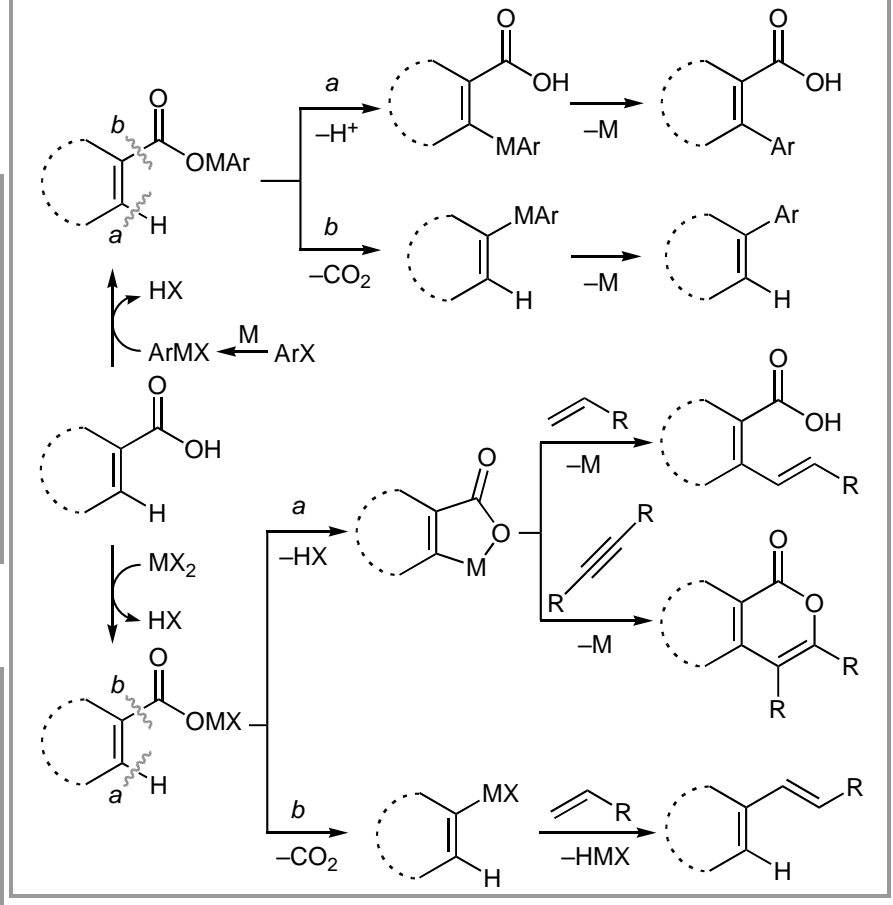

Scheme 7

\section{2 ortho- (cine-) Arylation}

In 2007, Yu and co-workers reported that the regioselective phenylation of benzoic acids at the ortho-position takes place by treatment with a phenylboronate in the presence of $\mathrm{Pd}(\mathrm{OAc})_{2}$, benzoquinone $/ \mathrm{Ag}_{2} \mathrm{CO}_{3}$, and $\mathrm{K}_{2} \mathrm{HPO}_{4}$ as catalyst, oxidant, and base, respectively (Scheme 8). ${ }^{18}$ Under similar conditions, aliphatic acids such as pivalic acid also undergo phenylation at the $\beta$ position, albeit with low efficiency.

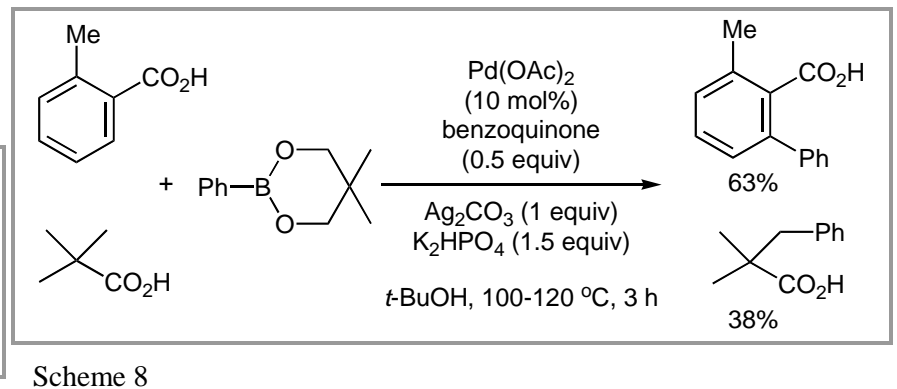

It has been suggested that this type of $\mathrm{C}-\mathrm{H}$ substitution reactions with the aid of a directing group using organometallic reagents proceeds through $\mathrm{Pd}^{\mathrm{II}} / \mathrm{Pd}^{0}$ catalysis. ${ }^{1 \mathrm{~d}}$ Thus, as shown in Scheme 9, the reaction begins with the formation of a palladacycle intermediate via coordination of the directing group (Y) to $\mathrm{Pd}^{\mathrm{II}} \mathrm{X}_{2}$ species and cyclopalladation. Transmetalation between the intermediate and organometallic reagent RM and the subsequent reductive elimination results in the formation of an ortho- (cine-) substituted product and $\mathrm{Pd}^{0}$ species. The latter is reoxidized to regenerate the active $\mathrm{Pd}^{\mathrm{II}}$ species. 


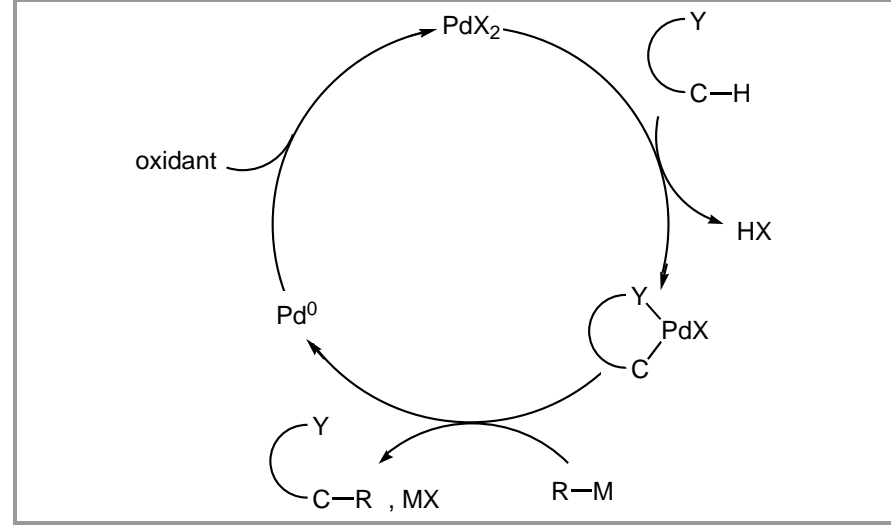

Scheme 9

Later, the ortho-arylation reactions of benzoic acids as well as phenylacetic acids with potassium aryltrifluoroborates have been disclosed (Scheme 10). ${ }^{19}$ These reactions proceed smoothly even under conditions using $\mathrm{O}_{2}$ or air $(20 \mathrm{~atm})$ in place of the silver salt as oxidant.

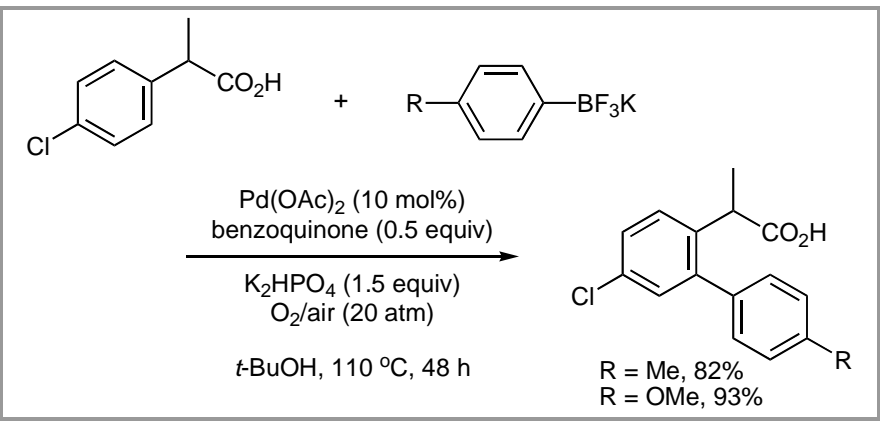

Scheme 10

Daugulis and co-workers reported that the orthoarylation of benzoic acids can also be conducted with aryl chlorides, which are less expensive and more widely available than the arylboron reagents (Scheme 11). ${ }^{20}$ bulky $\mathrm{PBu}(\text { adamantyl })_{2}$ ligand, gives an arylpalladium intermediate, followed by anionic ligand exchange with cesium benzoate to form an arylpalladium benzoate. Then, cyclopalladation and reductive elimination take place to release an ortho-arylated benzoate and regenerate $\mathrm{Pd}^{0}$ species. The high magnitude of $\mathrm{KIE}\left(\mathrm{k}_{\mathrm{H}} / \mathrm{k}_{\mathrm{D}}=\right.$ 4.4), observed in the reactions using ortho-deuterated benzoic acids, indicates that the rate-determining step may be the cyclopalladation step.

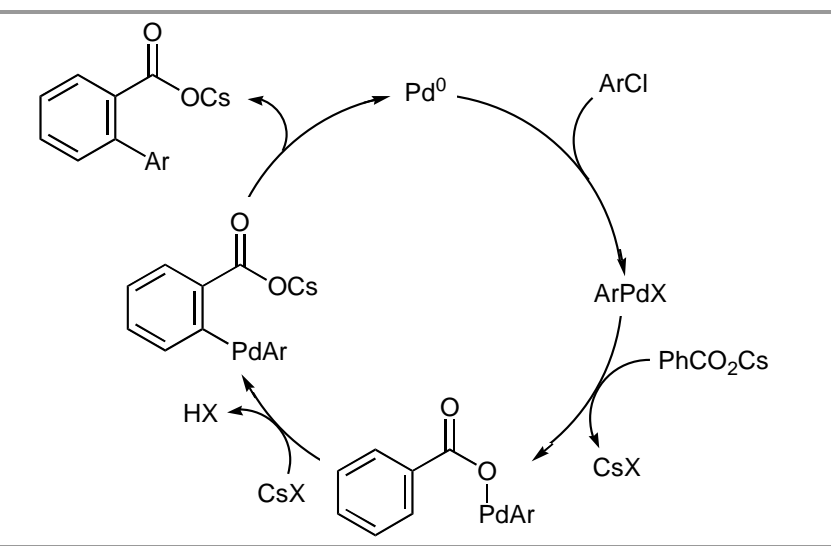

Scheme 12

As described in the introduction section, the carboxyl function acts not only as directing group but also as leaving group (Scheme 7). Therefore, it is conceivable that certain multiple arylations at the adjacent positions of the function can be realized under suitable conditions with palladium catalysis. Indeed, we succeeded in performing the perarylation of heteroarene carboxylic acids efficiently. The reaction of 3-thiophenecarboxylic acid with aryl bromides in the presence of a $\mathrm{Pd}(\mathrm{OAc})_{2} / \mathrm{PCy}_{3}$ catalyst system, $\mathrm{Cs}_{2} \mathrm{CO}_{3}$, and MS4A in refluxing mesitylene proceeds effectively to produce 1,2,3,4tetraarylthiophenes in fair to good yields (Scheme 13). ${ }^{21}$

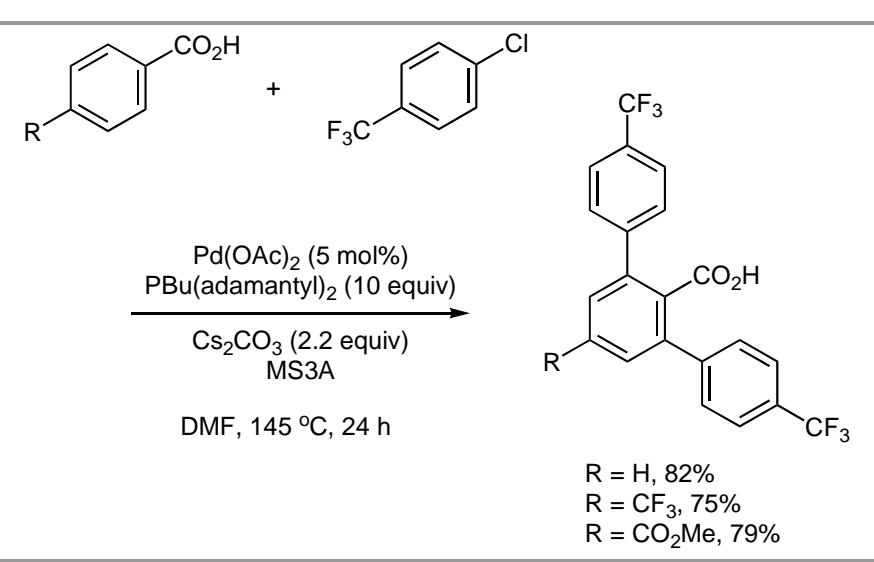

Scheme 11

The proposed reaction mechanism is illustrated in Scheme 12, which is similar to that for the orthoarylation of tert-benzyl alcohols via $\mathrm{Pd}^{0} / \mathrm{Pd}^{\mathrm{II}}$ catalysis (Scheme 2, path $a$ ). Thus, oxidative addition of $\mathrm{ArCl}$ toward $\mathrm{Pd}^{0}$ species, activated by an electron-donating,

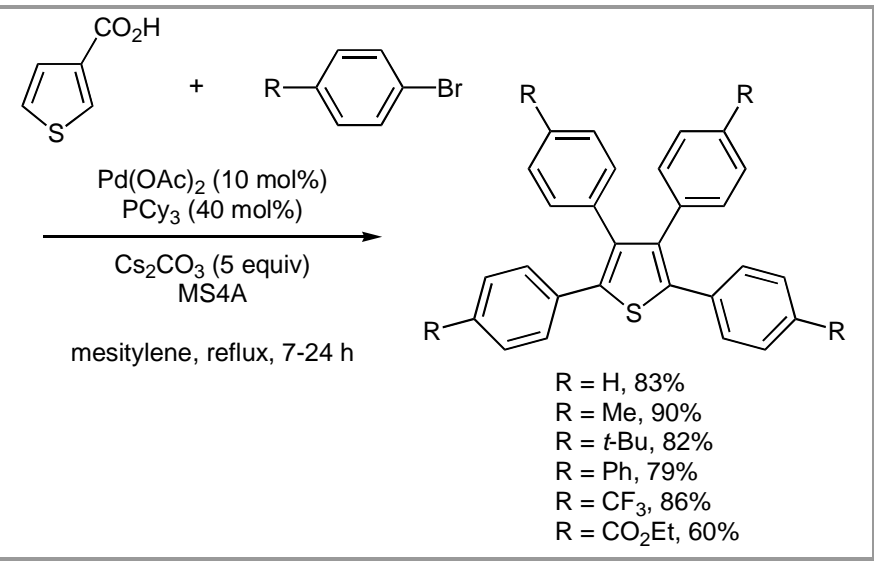

Scheme 13

At the electron-rich 2- and 5-positions on thiophene rings, the palladium-catalyzed direct arylation is known to take place. $^{22}$ In the tetraarylation of 3thiophenecarboxylic acid, this type of arylation (type $c$ ) seems to be involved as well as carboxyl-directed cine- 
arylation (type $a$ ) and ipso-arylation (type b) (Scheme 14).

type a: cine-arylation
type $b$ : ipso-arylation
type $c$ : direct arylation

Scheme 14

Plausible pathways for the formation of tetraarylthiophenes are depicted in Scheme 15. The cine-arylation (type $a$ ) at the 4-position appears to occur prior to the decarboxylative ipso-arylation (type $b$ ) at the 3-position. The direct arylation (type $c$ ) at the 2- and 5-positions may take place in any sequences.

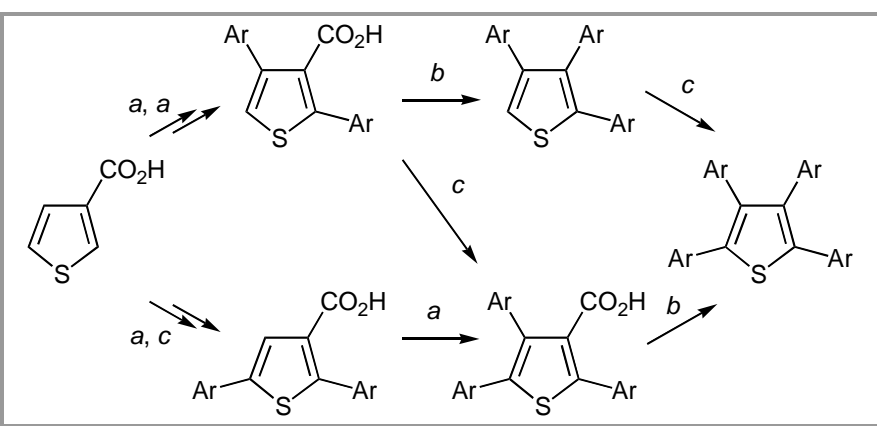

Scheme 15

Similarly, 3-furancarboxylic $\mathrm{acid}^{21}$ and 1-methyl-2indolecarboxylic acid ${ }^{23}$ also undergo tetra- and diarylation, respectively (Schemes 16 and 17).

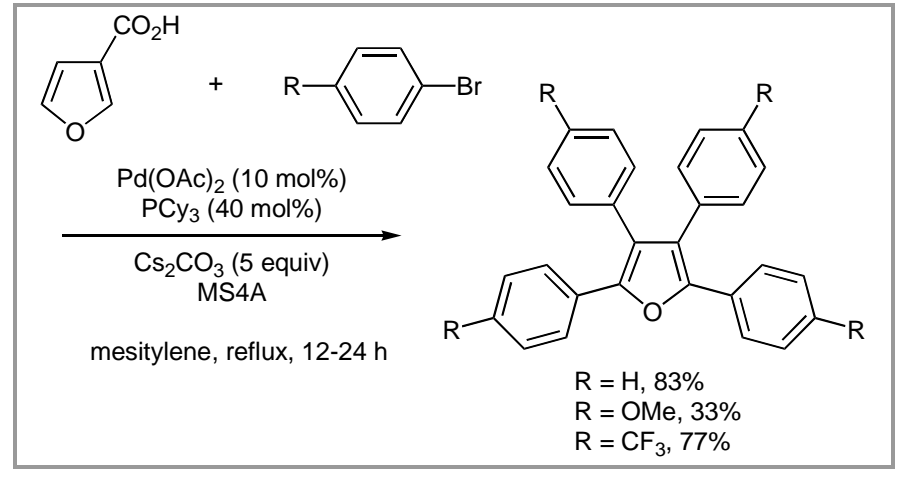

Scheme 16

$\mathrm{R}=\mathrm{OMe}, 33 \%$
$\mathrm{R}=\mathrm{CF}_{3}, 77 \%$

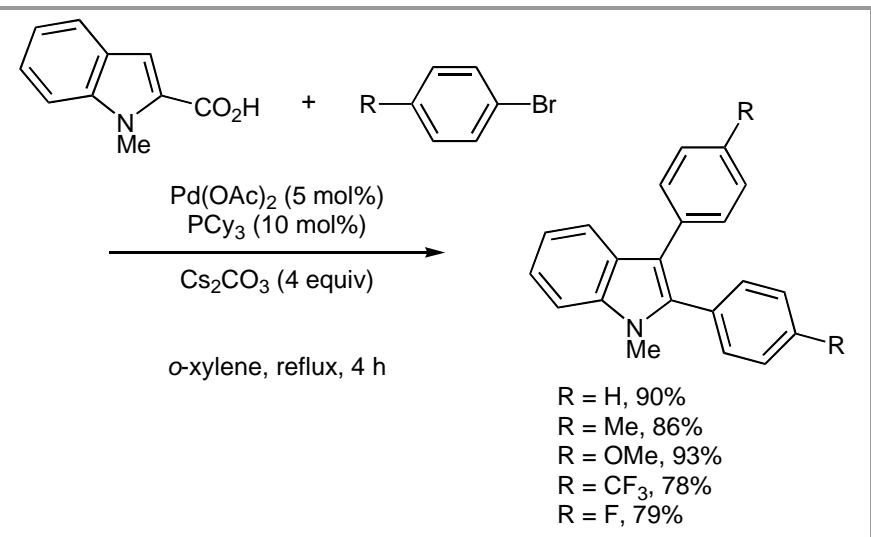

Scheme 17

3

\section{ortho- (cine-) Vinylation}

As shown in Scheme 6, we reported an early example for the ortho-vinylation of benzoic acid, in which the substrate oxidatively couples with butyl acrylate in a 1:1 manner under palladium catalysis to afford the corresponding phthalide derivative. ${ }^{15}$ In contrast, by using a rhodium catalyst in place of $\mathrm{Pd}$, the 1:2 coupling of these substrates involving disubstitution at both the orthopositions takes place selectively. ${ }^{24-26}$ Thus, treatment of benzoic acid with butyl or ethyl acrylate in the presence of $\left[\mathrm{Cp}^{*} \mathrm{RhCl}_{2}\right]_{2} \quad\left(1 \mathrm{mo} \%, \mathrm{Cp}^{*}=\eta^{5}-\right.$ pentamethylcyclopentadienyl) and $\mathrm{Cu}(\mathrm{OAc})_{2} \cdot \mathrm{H}_{2} \mathrm{O} \quad(5$ mol\%) under air affords 7-vinylphthalides (Scheme 18).

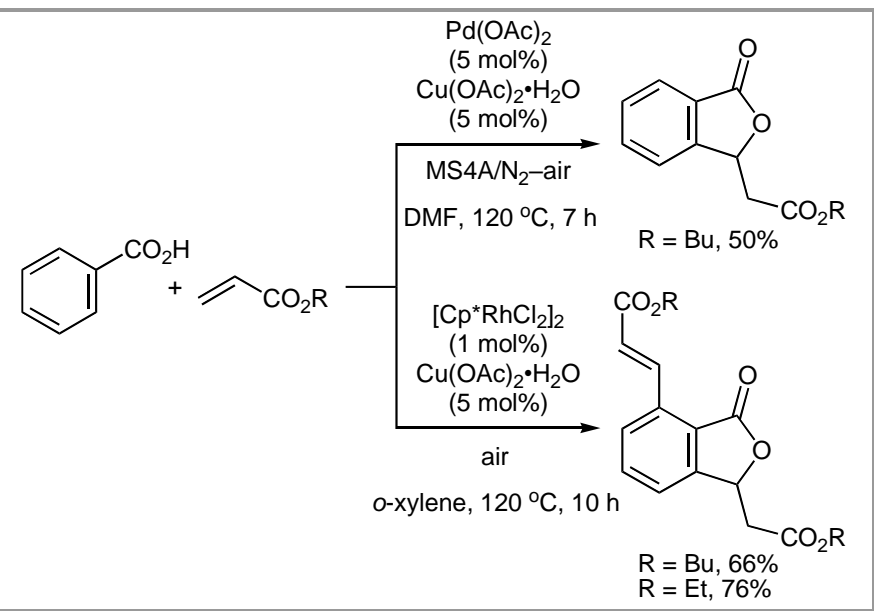

Scheme 18

A plausible mechanism for the rhodium-catalyzed divinylation of benzoic acid is illustrated in Scheme 19. Coordination of the carboxylate oxygen to $\mathrm{Cp}^{*} \mathrm{Rh}^{\mathrm{III}} \mathrm{X}_{2}$ species gives an $\mathrm{Rh}^{\mathrm{III}}$ benzoate $\mathbf{A}$. Subsequent cyclorhodation to form a rhodacycle intermediate $\mathbf{B},{ }^{12}$ alkene insertion, and $\beta$-hydride elimination occur to produce an ortho-monovinylated benzoic acid. The second vinylation takes place via similar steps to lead to a 2,6divinylated benzoic acid, which may undergo nucleophilic cyclization to form the final product. 


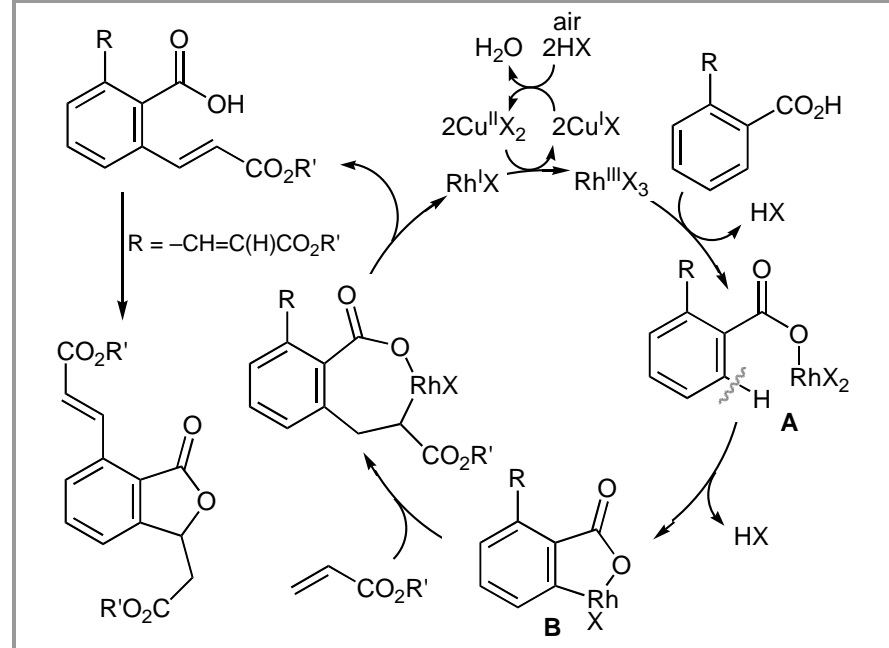

Scheme 19

In contrast to the acrylates, $N, N$-dimethylacrylamide and acrylonitrile react with benzoic acid in a 1:1 manner under similar conditions (Scheme 20). In the cases with these alkenes, the cyclization exclusively occurs after the first vinylation (see Scheme 19), as does in the palladium-catalyzed reaction. ${ }^{15}$

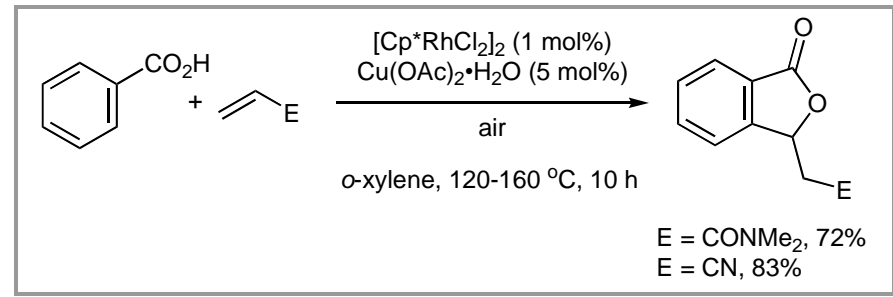

Scheme 20.

1-Methylindole-3-carboxylic acid undergoes similar cine-vinylation directed by its carboxyl function on treatment with acrylates in the presence of a palladium catalyst and a copper salt oxidant. ${ }^{27}$ On the heterocyclic system, interestingly, the subsequent decarboxylation ${ }^{28-34}$ takes place readily prior to the nucleophilic cyclization (Scheme 21).

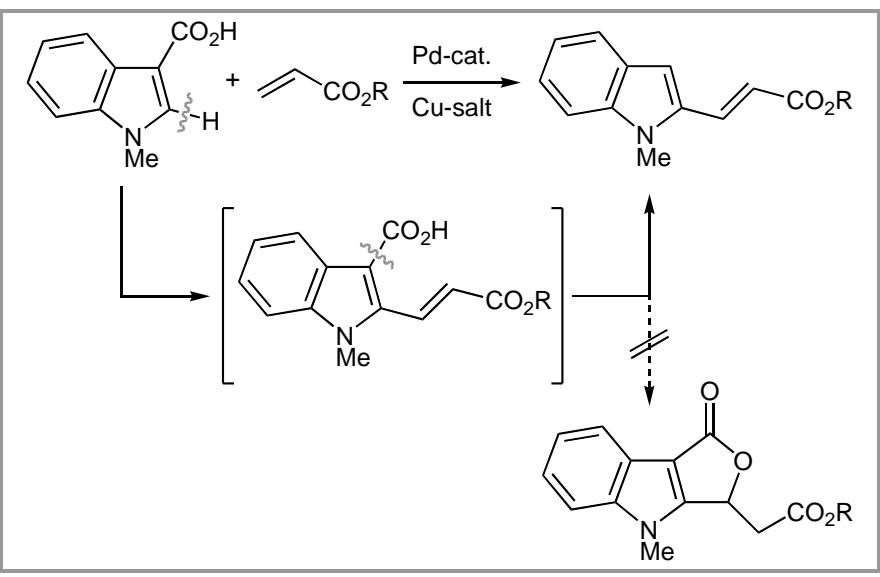

Scheme 21
This reaction proceeds smoothly by using stoichiometric or excess amounts of $\mathrm{Cu}(\mathrm{OAc})_{2} \bullet \mathrm{H}_{2} \mathrm{O}$ and $\mathrm{LiOAc}$ (Scheme 22). Without the latter additive, the product yields decrease to less than half.

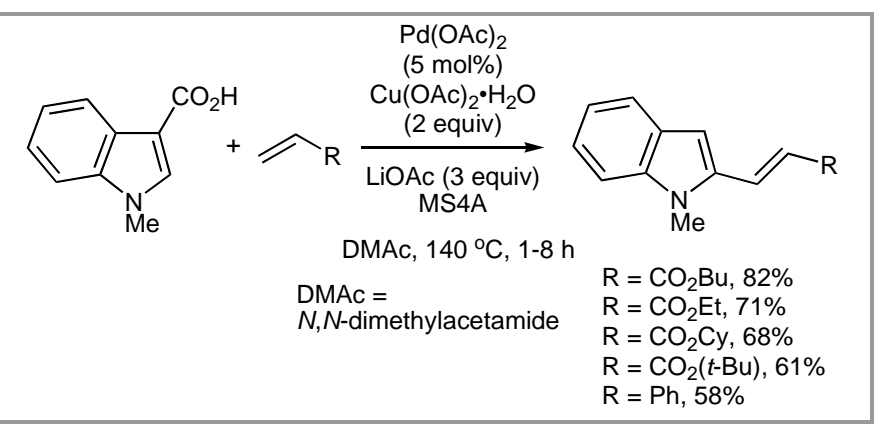

Scheme 22

It should be noted that the palladium-catalyzed direct vinylation (Fujiwara-Moritani reaction) of the parent indoles such as 1-methylindole usually occurs at the electron-rich C3-position due to the electrophilic nature of the reaction. ${ }^{35}$ Actually, under similar conditions with the $\mathrm{Pd}(\mathrm{OAc})_{2} / \mathrm{Cu}(\mathrm{OAc})_{2} \cdot \mathrm{H}_{2} \mathrm{O} / \mathrm{LiCl}$ system, 1methylindole reacts with butyl acrylate to give $\mathrm{C} 3$ vinylated product selectively (Scheme 23).

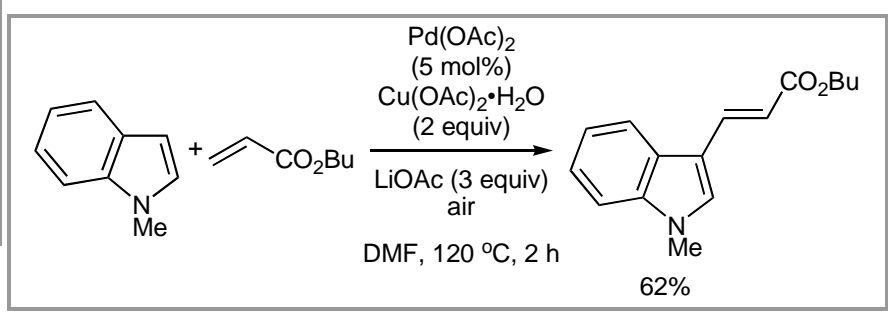

Scheme 23

Gaunt and co-workers reported the solvent-controlled regioselective vinylation of indoles by FujiwaraMoritani reaction. ${ }^{36}$ Thus, C3-vinylated products are produced almost exclusively in DMF/DMSO, whereas $\mathrm{C} 2$-vinylation takes place predominantly in dioxane/AcOH. However, the scope for the C2-vinylation is still limited and a relatively high palladium loading is required. The reaction of the carboxylic acid enables vinylation at a complimentary position to that of Fujiwara-Moritani reaction. Using this procedure, C3vinylation on pyrrole ${ }^{37}$ and benzofuran rings can also be achieved (Scheme 24), which are known to be more difficult in Fujiwara-Moritani reaction without the aid of the removable directing group. 


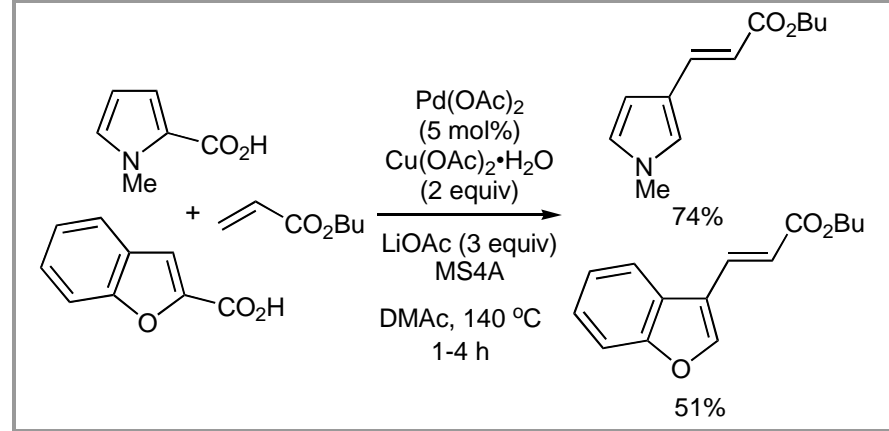

Scheme 24

In 2010, Yu and co-workers reported that phenylacetic acids undergo ortho-vinylation in the presence of $\mathrm{Pd}(\mathrm{OAc})_{2}$ (5 mol\%), benzoquinone (5 $\left.\mathrm{mol} \%\right)$, and $\mathrm{KHCO}_{3}$ (2 equiv) under oxygen (1 atm) in tert-amyl alcohol to afford the corresponding (2vinylphenyl)acetic acids (Scheme 25). ${ }^{38}$

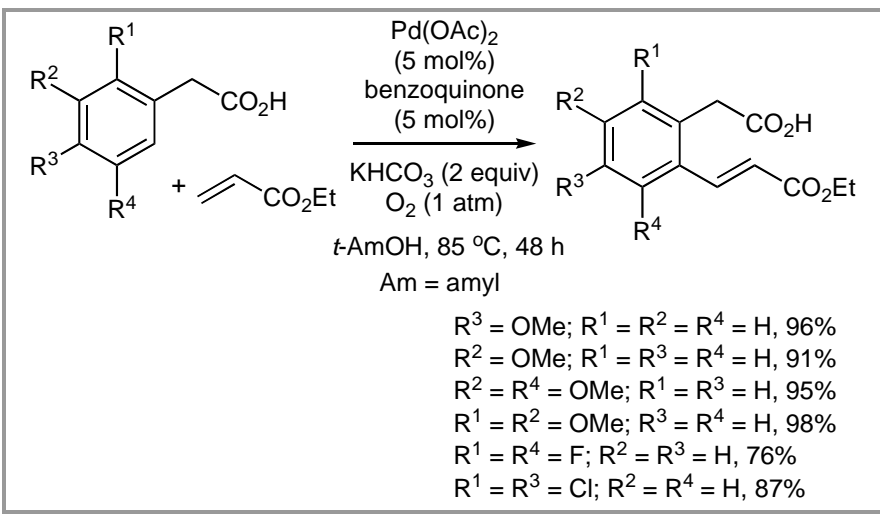

Scheme 25

In some cases, the regioselectivity of the vinylation on unsymmetrically substituted phenylacetic acids is enhanced by the addition of a suitable amino acid ligand, such as $N$-formylisoleuicine (Scheme 26).

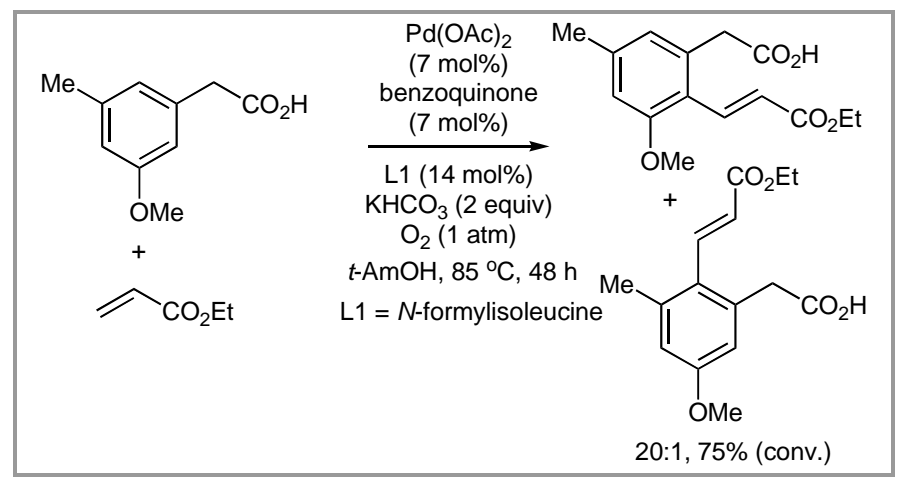

Scheme 26

By using a chiral amino acid ligand, the enantioselective vinylation of diphenylacetic acids can be achieved (Scheme 27). ${ }^{39} N$-Boc protected $L$-isoleuicine is the ligand of choice in this reaction.

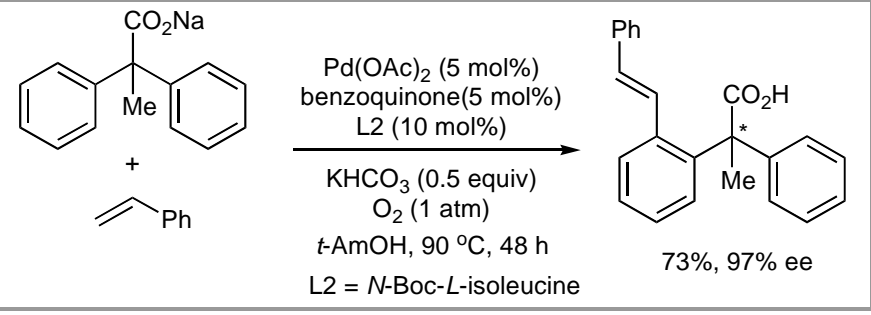

Scheme 27

Benzoic acids are found to couple not only with alkenes but also with alkynes oxidatively via the cleavage of ortho $\mathrm{C}-\mathrm{H}$ bond under rhodium catalysis. ${ }^{24-26}$ Thus, the reaction of benzoic acid with diphenylacetylene (1.2 equiv) proceeds efficiently in the presence of $\left[\mathrm{Cp} * \mathrm{RhCl}_{2}\right]_{2}(1 \mathrm{~mol} \%)$ and $\mathrm{Cu}(\mathrm{OAc})_{2} \bullet \mathrm{H}_{2} \mathrm{O}$ (2 equiv) under $\mathrm{N}_{2}$ in $o$-xylene to produce a 1:1 oxidative coupling product, 3,4-diphenylisocoumarin (Scheme 28). Dialkylacetylenes such as 4-octyne and 8-hexadecyne also undergo the coupling with benzoic acid effectively to afford the corresponding 3,4-dialkylisocoumarins in good yields. The reactions of unsymmetrical alkylphenylacetylenes give 4-alkyl-3-phenylisocoumarins predominantly. In these reactions, a rhodacycle intermediate B', generated in a similar manner to that in the reaction with alkenes (B in Scheme 19), may undergo alkyne insertion to form a seven-membered intermediate $\mathbf{C}$ and successive reductive elimination to form an isocoumarin.

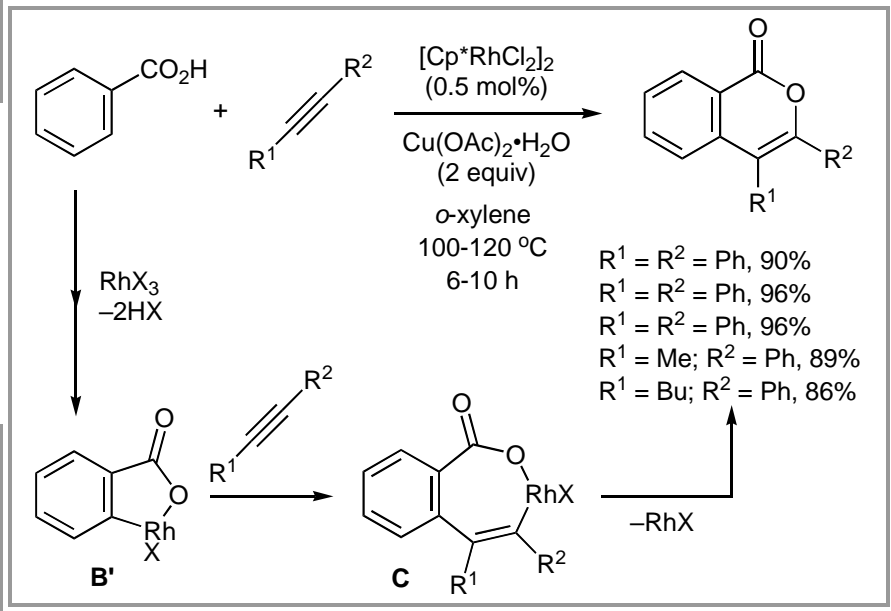

Scheme 28

From the same substrates, benzoic acids and alkynes, 1,2,3,4-tetrasubstituted naphthalenes can be exclusively produced as 1:2 coupling products by using $\left[\mathrm{Cp}^{*} \mathrm{IrCl}_{2}\right]_{2}$ and $\mathrm{Ag}_{2} \mathrm{CO}_{3}$ as catalyst and oxidant, respectively (Scheme 29). In these cases, a seven-membered iridacycle intermediate $\mathbf{C}^{\prime}$, generated in a similar manner to that in the rhodium-catalyzed reaction ( $\mathbf{C}$ in Scheme 28), may undergo decarboxylation rather than reductive elimination. Subsequently, the second alkyne insertion and reductive elimination take place to produce a tetrasubstituted naphthalene. 


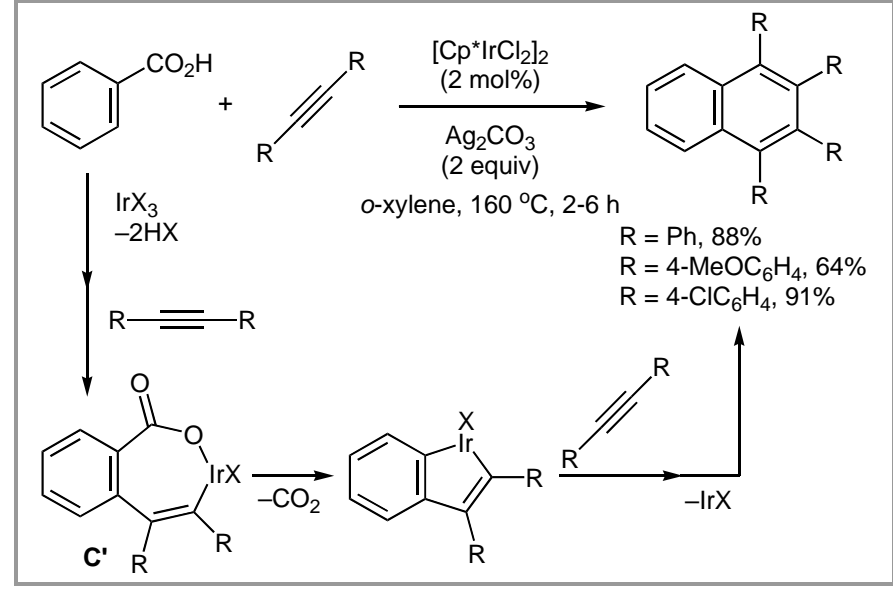

Scheme 29

Besides benzoic acids, heteroarene carboxylic acids also undergo the 1:1 coupling with diphenylacetylene in DMF under rhodium catalysis. ${ }^{40}$ As shown in Scheme 30, bi- and tricyclic fused heteroaromatic systems can be constructed effectively through the process.

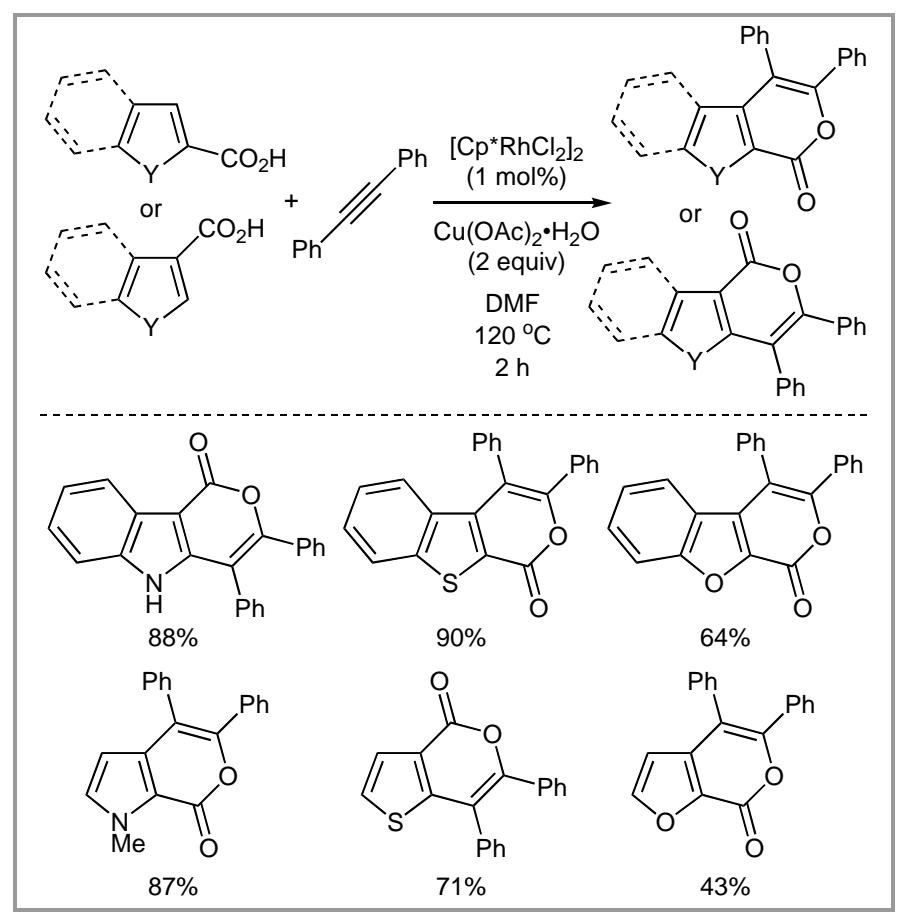

Scheme 30

In contrast to benzoic acids (Scheme 29), heteroarene carboxylic acids such as 1-methylindole-3-carboxylic acid hardly undergo the decarboxylative 1:2 coupling with the iridium catalyst (Scheme 31, path a). To our delight, the 1:2 coupling was found to proceed efficiently by the use of a palladium catalyst in place of Ir to produce the corresponding 1,2,3,4-tetrasubstituted carbazole derivatives selectively (path $b$ ). ${ }^{41,42}$

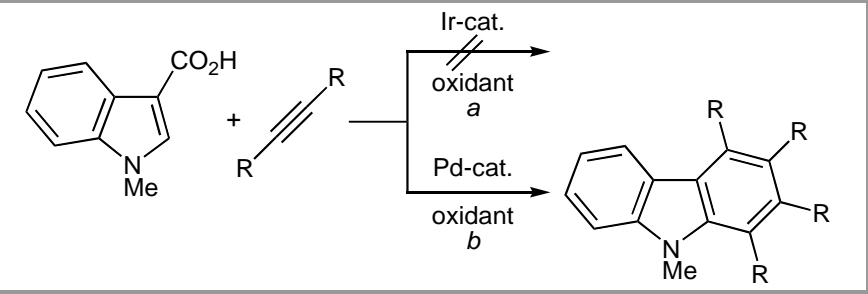

Scheme 31

In the presence of $\mathrm{Pd}(\mathrm{OAc})_{2}(5 \mathrm{~mol} \%), \mathrm{Cu}(\mathrm{OAc})_{2} \cdot \mathrm{H}_{2} \mathrm{O}$ ( 2 equiv), LiOAc ( 3 or 6 equiv), and molecular sieves (MS4A), indole, pyrrole, and benzofurancarboxylic acids react with diphenylacetylene to afford carbazole, indole, and dibenzofuran derivatives, respectively (Scheme 32). In the reaction of benzofurancarboxylic acid, a better product yield can be obtained by using $\mathrm{LiOH} \cdot \mathrm{H}_{2} \mathrm{O}(3$ equiv) and 2,2-dimethylsuccinic acid (6 equiv) in place of $\mathrm{LiOAc}$.

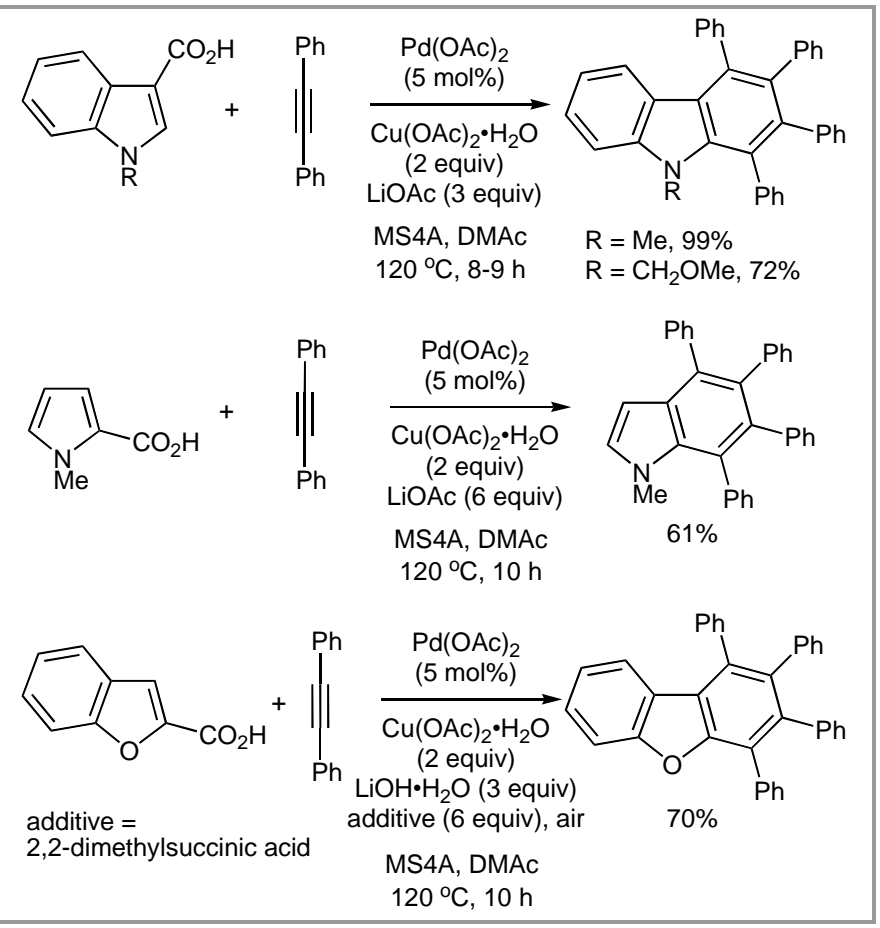

Scheme 32

1-Phenylindole-3-carboxylic acid undergoes a unique $1: 1$ coupling with diarylacetylene under similar conditions via double $\mathrm{C}-\mathrm{H}$ bond cleavage and decarboxylation to produce 5,6-diarylindolo[1,2-a]quinolines predominantly (Scheme 33). 


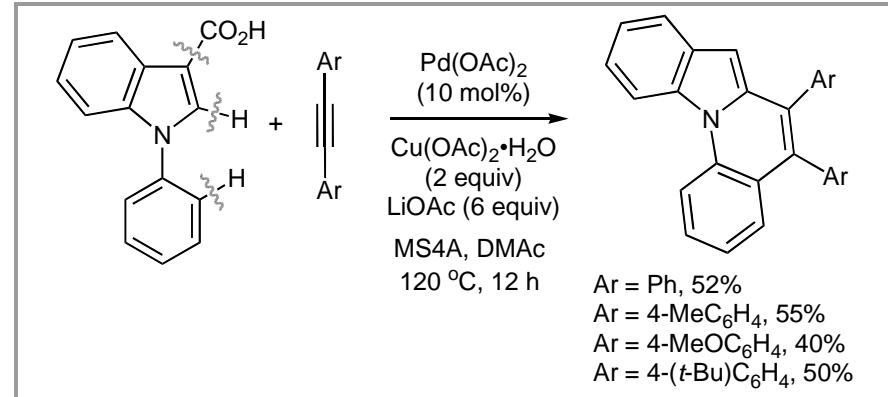

Scheme 33

Interestingly, the rhodium-catalyzed 1:1 coupling of benzoic acids with alkynes takes place efficiently even with a catalytic amount $(5 \mathrm{~mol} \%)$ of $\mathrm{Cu}(\mathrm{OAc})_{2} \bullet \mathrm{H}_{2} \mathrm{O}$ under air. Thus, the aerobic oxidative coupling using a catalyst system of $\left[\mathrm{Cp}^{*} \mathrm{RhCl}_{2}\right]_{2} / \mathrm{Cu}(\mathrm{OAc})_{2} \cdot \mathrm{H}_{2} \mathrm{O}$ proceeds in DMF to afford isocoumarins in good to excellent yields (Scheme 34). In particular, anthranilic- and salicylic acid derivatives smoothly undergo the reaction to produce 8 -amino- and 8-hydroxyisoquinolines, which are known to exhibit interesting biological and photochemical properties. ${ }^{43-47}$

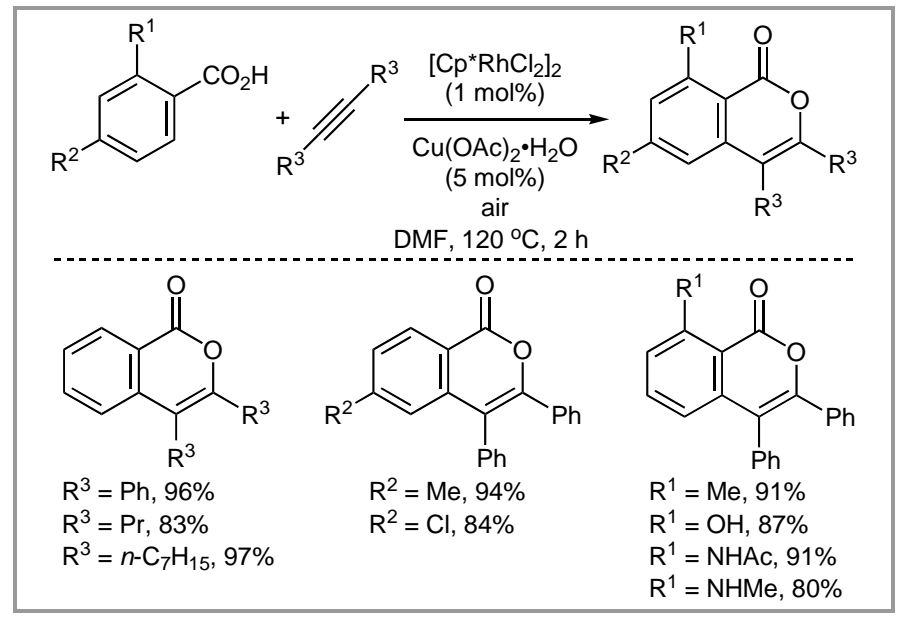

Scheme 34

$\mathrm{N}$-Phenylanthranilic acid also reacts with diarylacetylenes under the aerobic conditions in $o$-xylene to form the corresponding 8 -( $N$-phenylamino)isocoumarins in good yields (Scheme 35$).{ }^{40}$ However, the use of a different rhodium catalyst system, $[\mathrm{RhCl}(\mathrm{cod})]_{2} / \mathrm{C}_{5} \mathrm{H}_{2} \mathrm{Ph}_{4}$, in place of $\left[\mathrm{Cp} * \mathrm{RhCl}_{2}\right]_{2}$ dramatically changes the reaction pathway (cod = 1,5-cyclooctadiene, $\mathrm{C}_{5} \mathrm{H}_{2} \mathrm{Ph}_{4}=1,2,3,4$ tetraphenyl-1,3-cyclopentadiene). Thus, the reaction with this catalyst in DMF proceeds through double $\mathrm{C}-\mathrm{H}$ bond cleavage and decarboxylation to afford 4-(1,2diarylethenyl)- $9 H$-carbazoles.

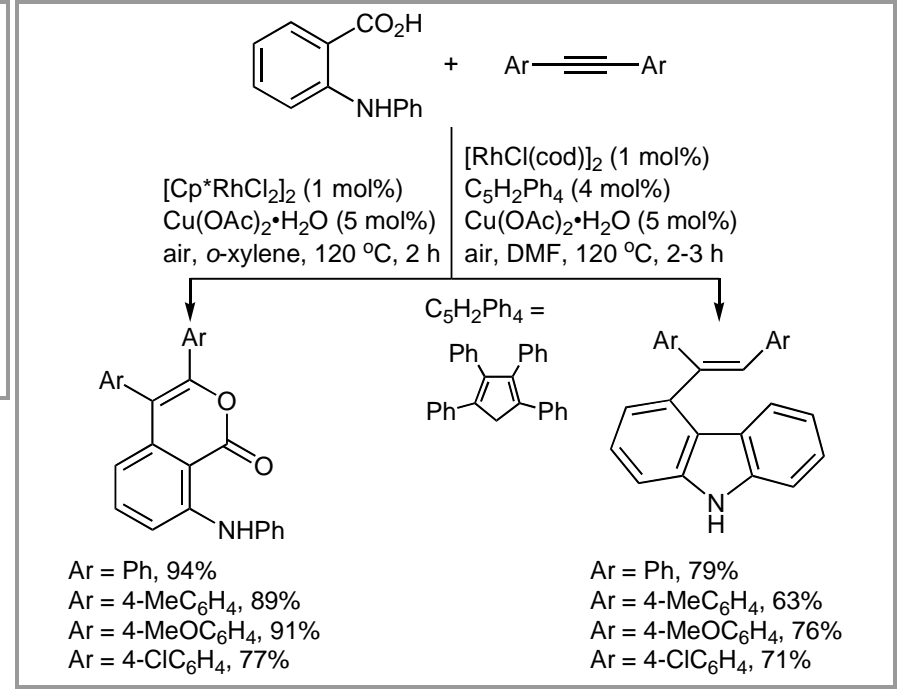

Scheme 35

Under rhodium catalysis, acrylic acids such as methacrylic acid also oxidatively couple with alkenes and alkynes through vinylic $\mathrm{C}-\mathrm{H}$ bond cleavage (Scheme 36). ${ }^{48}$ These reactions using stoichiometric amounts of $\mathrm{Ag}_{2} \mathrm{CO}_{3}$ or $\mathrm{Cu}(\mathrm{OAc})_{2} \cdot \mathrm{H}_{2} \mathrm{O}$ as oxidant give $\alpha$-pyrone and butenolide derivatives.

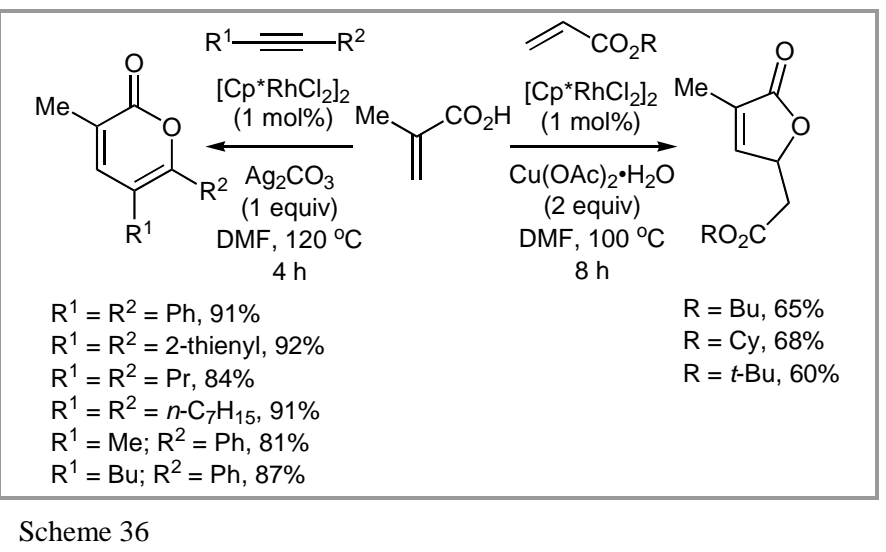

4 ipso-Arylation

The transition-metal-catalyzed cross-coupling of aryl halides with arylmetal reagents such as arylboronic acids has been recognized to be one of the most powerful methods for constructing biaryl structures, ${ }^{49}$ which are found in a wide range of important compounds including natural products and organic functional materials. However, the organometallic reagents are usually prepared from air- and moisture-sensitive precursors to be expensive. Recently, during our study of the palladiumcatalyzed decarbamoylation/arylation of thiophencarboxamides with aryl bromides, ${ }^{50}$ we observed that 3phenylbenzothiophene-2-carboxylic acid underwent the regioselective phenylation under similar conditions with bromobenzene accompanied by decarboxylation to form 2,3-diphenylbenzothiophene. ${ }^{50,51}$ As a further earlier 
example, Steglich and co-workers reported the stoichiometric intramolecular version of the decarboxylative arylation on only one substrate. ${ }^{52}$ In contrast to arylmetal reagents, arene and heteroarene carboxylic acids are an attractive aryl source because of their wide availability and stability. Later, the decarboxylative coupling of various carboxylic acids with aryl halides has been developed.

In 2006, Forgione, Bilodeau, and co-workers reported that a remarkably wider range of heteroarene carboxylic acids undergo the decarboxylative ipso-arylation. ${ }^{53,54} \mathrm{As}$ shown in Scheme 37, treatment of 1-methylpyrrole-2carboxylic acid with aryl bromides in the presence of $\mathrm{Pd}\left[\mathrm{P}(t-\mathrm{Bu})_{3}\right]_{2}(5 \mathrm{~mol} \%), \mathrm{Bu}_{4} \mathrm{~N}^{+} \mathrm{Cl}^{-} \cdot \mathrm{H}_{2} \mathrm{O}$ (1 equiv), and $\mathrm{Cs}_{2} \mathrm{CO}_{3}$ (1.5 equiv) in DMF under microwave heating at $170{ }^{\circ} \mathrm{C}$ for $8 \mathrm{~min}$ produces 2-aryl-1-methylpyrroles.<smiles>O=C(O)c1cccn1[Na]</smiles>
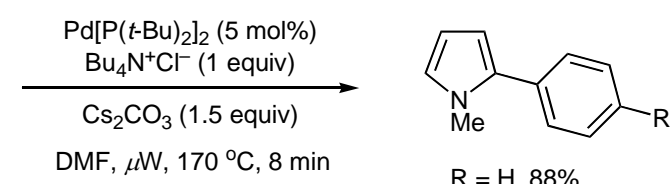

$\mathrm{R}=\mathrm{H}, 88 \%$

$\mathrm{R}=\mathrm{OMe}, 77 \%$

$\mathrm{R}=\mathrm{NO}_{2}, 66 \%$

Scheme 37

The ipso-arylation, which is included in the perarylation described above (Schemes 14 and 15, type $b$ ), seems to proceed via i) oxidative addition of $\mathrm{ArBr}$ toward $\mathrm{Pd}^{0}$ species generated in situ, ii) coordination of carboxyl oxygen, iii) decarboxylation, and iv) reductive elimination (Scheme 38).

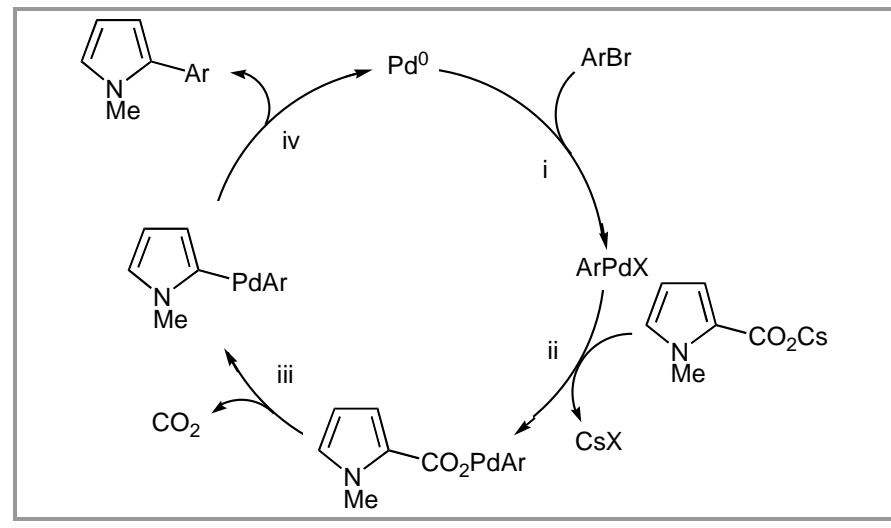

Scheme 38

In the same year, Gooßen and co-workers disclosed that 2-substituted benzoic acids also undergo the decarboxylative coupling with aryl bromides in the presence of $\operatorname{Pd}(\mathrm{acac})_{2}(1 \mathrm{~mol} \%), \mathrm{CuI}(3 \mathrm{~mol} \%), 1,10$-phenanthroline (5 mol\%), $\mathrm{K}_{2} \mathrm{CO}_{3}$ (1.2 equiv), and MS3A in NMP at 160 ${ }^{\circ} \mathrm{C}$ to form the corresponding biaryls (Scheme 39). ${ }^{55,56}$ Without the nitro group or other coordinating substitu- ents at the ortho-position of benzoic acids, the reaction becomes sluggish.

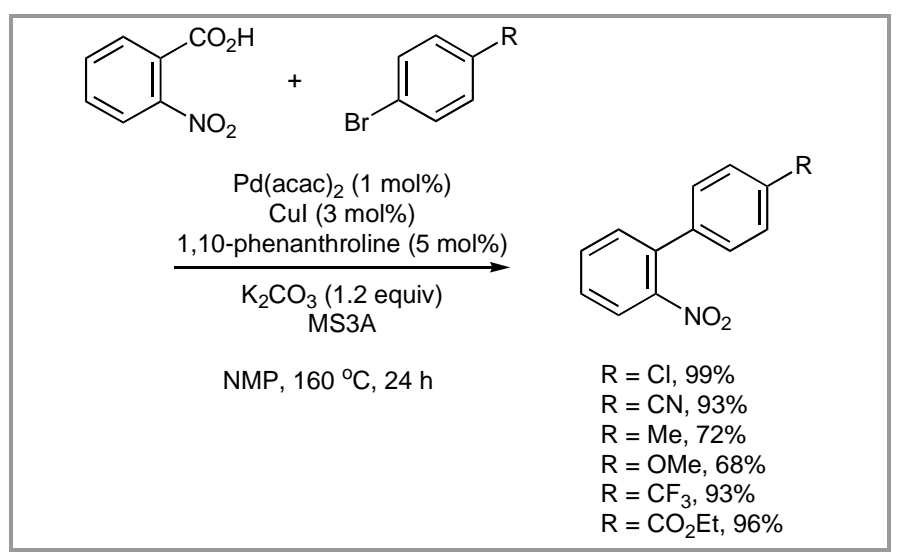

Scheme 39

Becht, Wagner, and co-workers showed that the coupling of even electron-rich benzoic acids with aryl iodides can be conducted efficiently by using a $\mathrm{PdCl}_{2} / \mathrm{AsPh}_{3}$ catalyst system in the presence of $\mathrm{Ag}_{2} \mathrm{CO}_{3}$ as base. ${ }^{57,58}$

Liu and co-workers reported that potassium perfluorobenzoates undergo the decarboxylative coupling wih aryl iodides and bromides even under copper catalysis in the absence of Pd. ${ }^{59}$ Thus, pentafluorobiphenyl can be produced in excellent yields under simple conditions using $\mathrm{CuI}(10 \mathrm{~mol} \%)$ in diglyme at $130{ }^{\circ} \mathrm{C}$ (Scheme 40$)$.

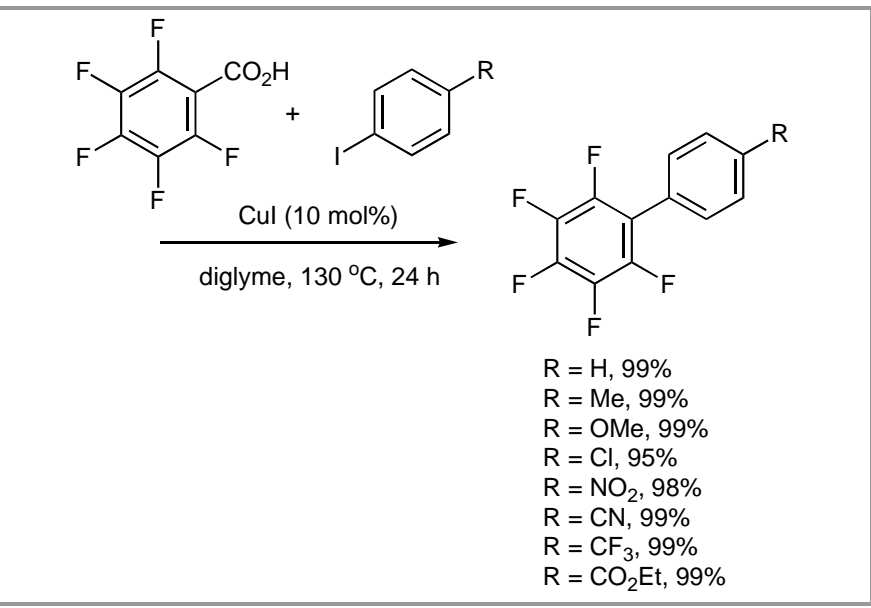

Scheme 40

Gooßen and co-workers also demonstrated that aryl chlorides can be employed as the coupling partner with electron-deficient, 2-substituted benzoic acids in the presence of a $\mathrm{Pd}$-based catalyst system, $\mathrm{PdI}_{2} / \mathrm{CuI} /(o$ biphenyl $) \mathrm{P}(t-\mathrm{Bu})_{2} / 1,10$-phenanthroline. ${ }^{60}$ Recently, a copper-free catalyst system, $\mathrm{Pd}(\mathrm{acac})_{2} / \mathrm{P}(o \text {-tolyl })_{3}$ was shown to be effective in the decarboxylative coupling of pyrrole-2-carboxylic acid derivatives with arene dibromides as a conjugated oligomer synthesis. ${ }^{61}$

The decarboxylative arylation of ortho-unsubstituted benzoic acids can be achieved by using aryl triflates in 
place of aryl halides. ${ }^{62,63}$ For example, potassium 3nitrobenzoate reacts with various aryl triflates (2 equiv) smoothly in the presence of $\mathrm{PdBr}_{2}(3 \mathrm{~mol} \%), \mathrm{Cu}_{2} \mathrm{O}$ (7.5 mol\%), Tol-BINAP (4.5 mol\%, Tol-BINAP = 2,2'bis(di-p-tolylphosphino)-1,1'-binaphthyl), and 1,10phenanthroline $(10 \mathrm{~mol} \%)$ in NMP at $170{ }^{\circ} \mathrm{C}$ to form the corresponding biaryls (Scheme 41 ). The reaction temperature can be reduced to $130{ }^{\circ} \mathrm{C}$, when a $\mathrm{Pd} / \mathrm{Ag}$ catalyst is employed. ${ }^{64}$

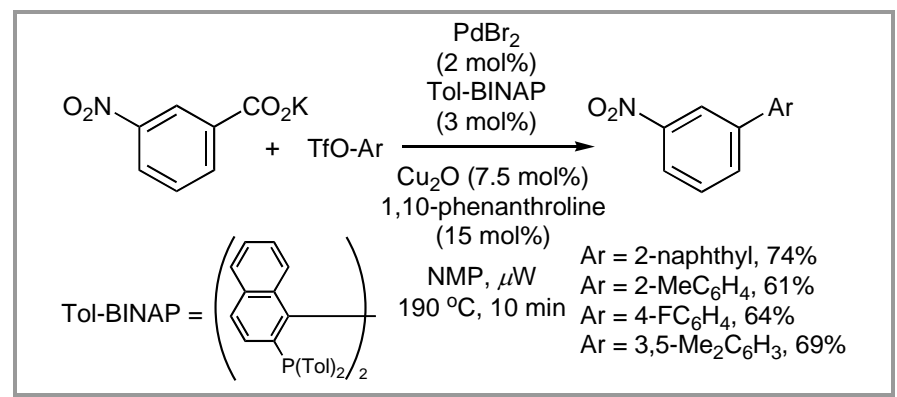

Scheme 41

Less expensive aryl tosylates also undergo the decarboxylative coupling with potassium benzoates (Scheme 42). ${ }^{65}$ In these cases, XPhos (XPhos $=2$ -

dicyclohexylphosphino-2',4',6'-triisopropylbiphenyl) is the ligand of choice.

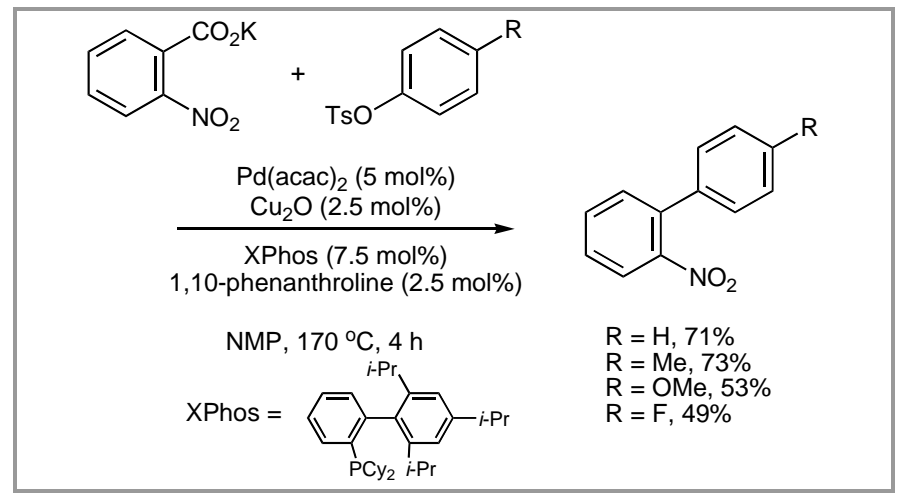

Scheme 42

From atom- and step-economical points of view, arenes and heteroarenes without prefunctionalization are more attractive coupling partners in the decarboxylative coupling, compared with aryl halides and sulfonates. So far, few examples with restricted substrates have appeared in recent papers. Crabtree and co-workers reported that 2,6dimethoxybenzoic acid couples with 2-phenylpyridine under the conditions using $\mathrm{Pd}(\mathrm{OAc})_{2}(10 \mathrm{~mol} \%),(t-\mathrm{Bu})-$ XPhos (20 mol\%, $(t$-Bu)-XPhos $=2$-di-tert-

butylphosphino-2',4',6'-triisopropylbiphenyl), $\mathrm{Ag}_{2} \mathrm{CO}_{3}$ (1.1 equiv), and MS4A in DMF/DMSO with microwave heating at $200{ }^{\circ} \mathrm{C}$ for $5 \mathrm{~min}$ accompanied by decarboxylation and regioselective $\mathrm{C}-\mathrm{H}$ bond cleavage to afford a 2-(biphenylyl)pyridine derivative (Scheme 43). ${ }^{66}$ Related decarboxylative arylation using aroyl peroxides on 2phenylpyridines is applicable to a wider synthesis. ${ }^{67}$

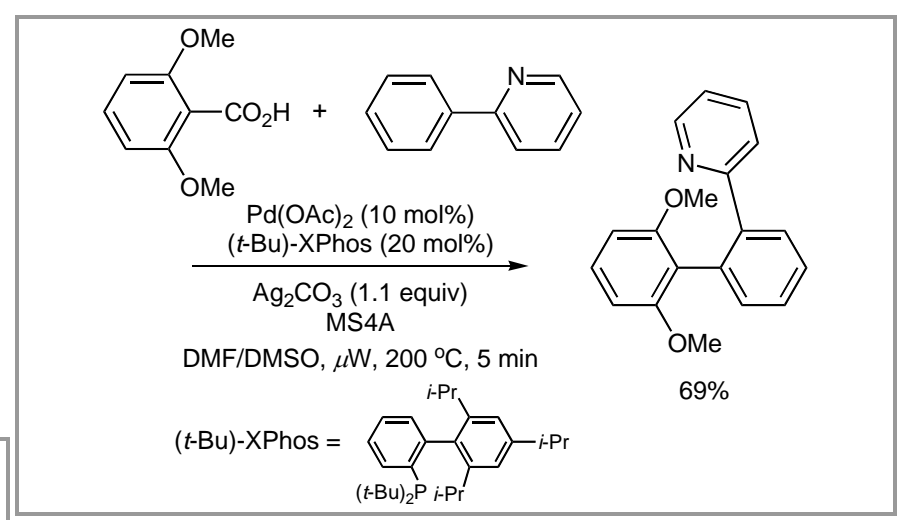

Scheme 43

Larrosa and co-workers disclosed the decarboxylative coupling of benzoic acids bearing ortho electronwithdrawing groups with indoles on their C3-carbon (Scheme 44). ${ }^{68}$

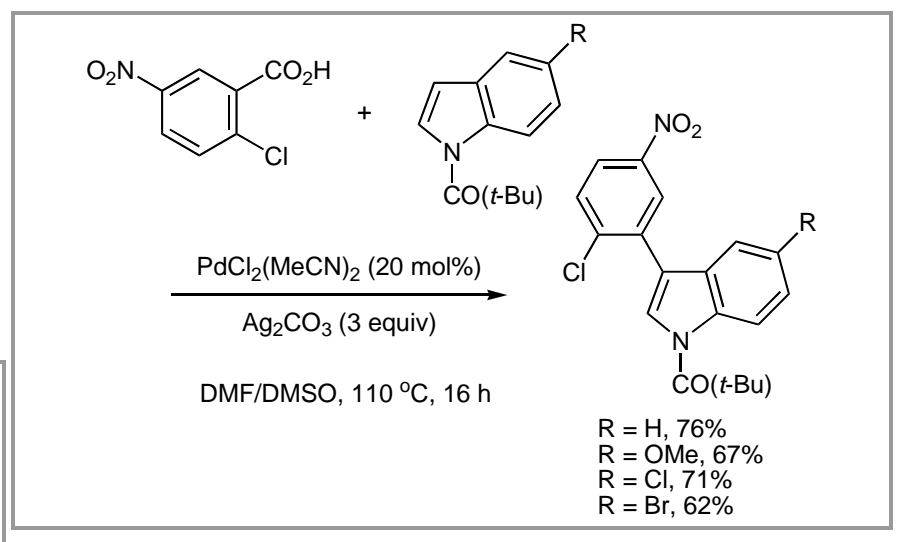

Scheme 44

Azoles also undergo the decarboxylative arylation at their 2-position on treatment with ortho-substituted benzoic acids in the presence of $\mathrm{PdCl}_{2}$ (20 mol\%), $\mathrm{PPh}_{3}(40$ $\mathrm{mol} \%$ ), and $\mathrm{Ag}_{2} \mathrm{CO}_{3}$ (3 equiv) in DMSO at $130{ }^{\circ} \mathrm{C}$ for 12 h (Scheme 45). ${ }^{69}$

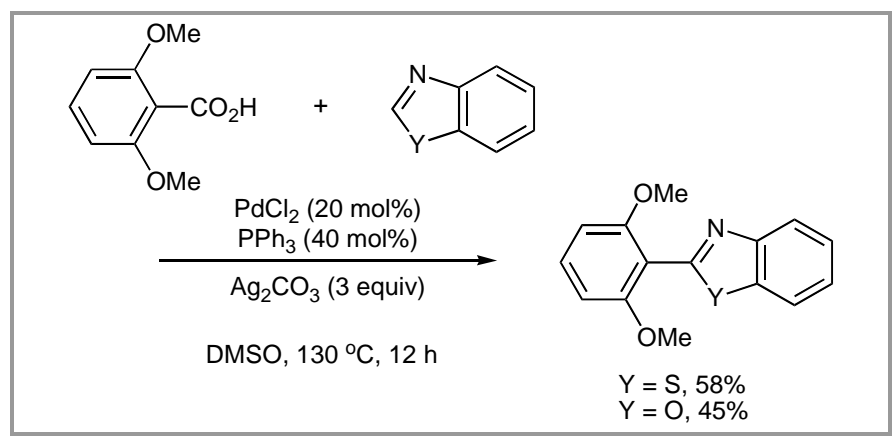

Scheme 45

The intramolecular version for preparing dibenzofuran derivatives from 2-phenoxybenzoic acids was reported by Glorius and co-workers (Scheme 46). ${ }^{70}$ 


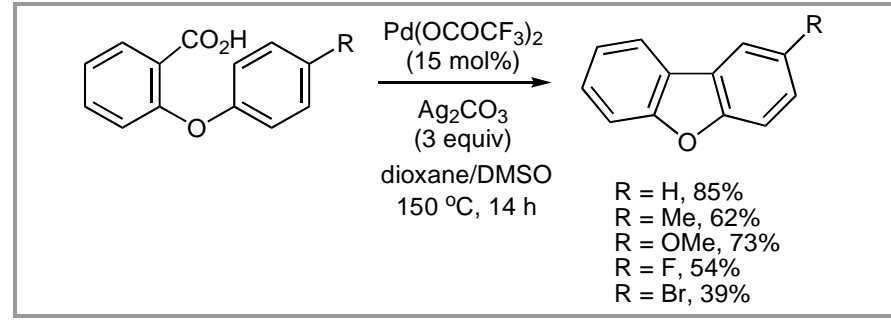

Scheme 46

Besides arene and heteroarene carboxylic acids, electron-deficient and -neutral cinnamic acids decarboxylatively couple with aryl iodides in the presence of $\mathrm{PdCl}_{2}$ (10 mol\%), CyJohnPhos (20 mol\%, CyJohnPhos $=2$ dicyclohexylphosphinobiphenyl), and $\mathrm{Ag}_{2} \mathrm{CO}_{3}$ (3 equiv) in DMAc (DMAc $=N, N$-dimethylacetamide) at $150{ }^{\circ} \mathrm{C}$ to afford stilbenes (Scheme 47), as reported by $\mathrm{Wu}$ and co-workers. ${ }^{71}$

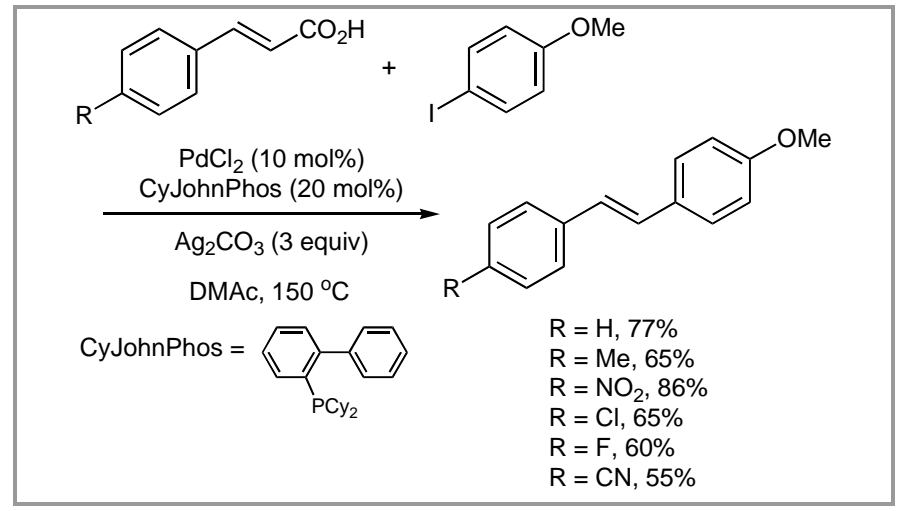

Scheme 47

Electron-rich cinnamic acids including ferulic acid (4hydroxy-3-methoxycinnamic acid) also undergo the decarboxylative arylation upon treatment with arylboronic acids in the presence of $\mathrm{Pd}(\mathrm{acac})_{2}(5 \mathrm{~mol} \%)$, $\mathrm{Cu}(\mathrm{OAc})_{2} \bullet \mathrm{H}_{2} \mathrm{O}$ (2 equiv) and $\mathrm{LiOAc}$ (4 equiv) in DMF to produce the corresponding hydroxylated stilbene derivatives (Scheme 48), ${ }^{72}$ which are of considerable interest due to their interesting biological ${ }^{73-75}$ and photophysical properties. ${ }^{76-78}$ Particularly, the decarboxylative reaction of ferulic acid readily takes place even under mild conditions at $60{ }^{\circ} \mathrm{C}$. It should also be noted that the starting materials, hydroxylated cinnamic acids, are widely present in plants and are readily available from biomass as building blocks for high-volume manufacturing. ${ }^{79-81}$

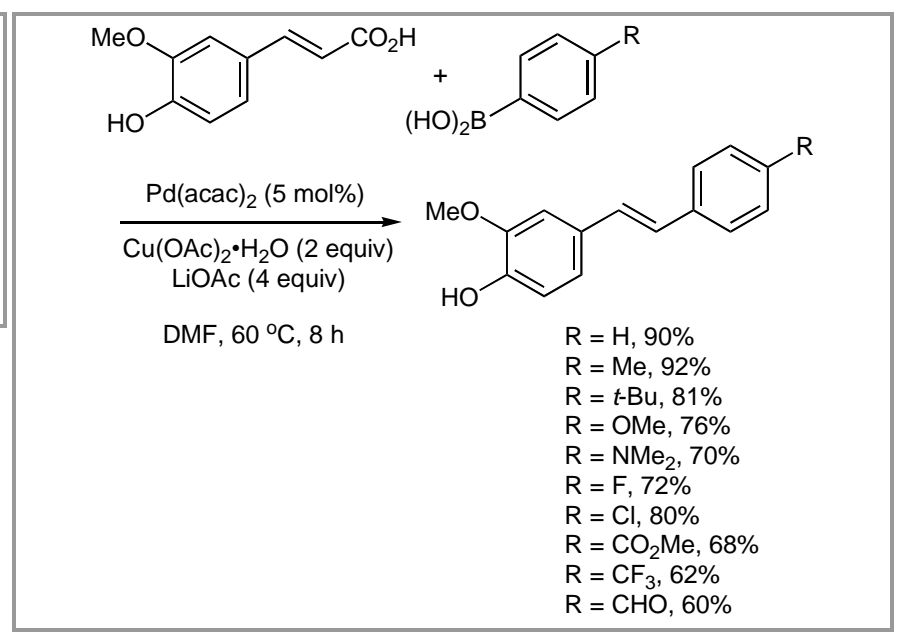

Scheme 48

Similar decarboxylative arylation of 5-phenyl-1,3pentadienoic acid proceeds efficiently at $40^{\circ} \mathrm{C}$ (Scheme 49).

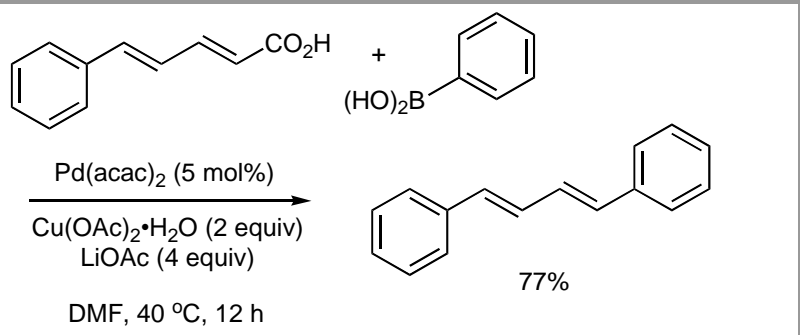

Scheme 49

The one-pot synthesis of unsymmetrical diarylacetylenes from propiolic acid and two kinds of aryl halides via a combination of Sonogashira and decarboxylative couplings has been conducted by Lee and co-workers (Scheme 50). ${ }^{82,83}$ An excess amount of TBAF (6 equiv) is employed as base, together with the catalyst system of $\mathrm{Pd}_{2}(\mathrm{dba})_{3}(5 \mathrm{~mol} \%, \mathrm{dba}=$ dibenzylideneacetone $)$ and dppf $\left(10 \mathrm{~mol} \%\right.$, dppf $=1,1^{\prime}-$

bis(diphenylphosphino)ferrocene).

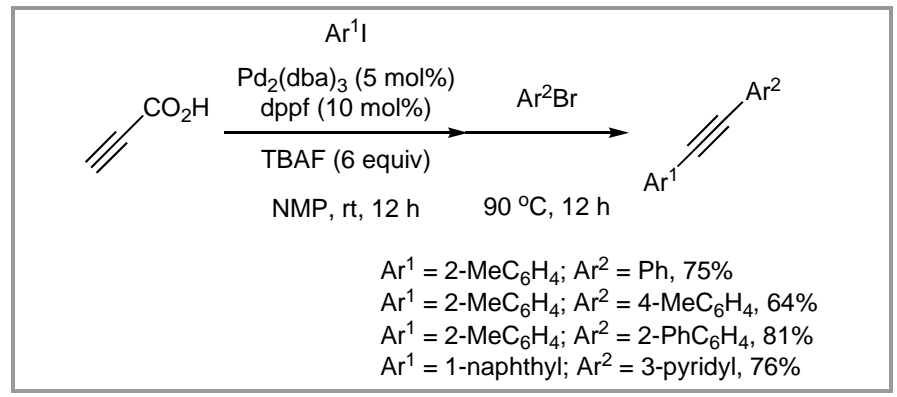

Scheme 50

The decarboxylative coupling of various $\alpha, \beta$-ynic acids with aryl and vinyl halides and triflates also proceeds smoothly. For example, 3-phenylpropiolic acid couples with $\beta$-bromostyrene in the presence of $\mathrm{Pd}_{2}(\mathrm{dba})_{3} \cdot \mathrm{CHCl}_{3}$ ( $2 \mathrm{~mol} \%)$, XantPhos (8 mol\%, XantPhos $=4,5-$ 
bis(diphenylphosphino)-9,9-dimethylxanthene), $\mathrm{Ag}_{2} \mathrm{O}$ (1.2 equiv), and $\mathrm{LiCl}$ (3 equiv) in $\mathrm{DMF}$ at $80^{\circ} \mathrm{C}$ to afford (E)-1,4-diphenyl-1-buten-3-yne in 92\% yield (Scheme 51). ${ }^{84}$

$\mathrm{Ph}$

$$
\frac{\begin{array}{c}
\mathrm{Pd}_{2}(\mathrm{dba})_{3} \cdot \mathrm{CHCl}_{3}(2 \mathrm{~mol} \%) \\
\text { XantPhos }(8 \mathrm{~mol} \%)
\end{array}}{\underset{\mathrm{Ag}_{2} \mathrm{CO}_{3} \text { (1.2 equiv) }}{\mathrm{LiCl} \text { (3 equiv) }}}
$$

DMF, $80^{\circ} \mathrm{C}, 2 \mathrm{~h}$

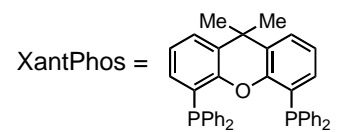

Scheme 51

Gooßen and co-workers showed that $\alpha$-oxocarboxylic acids undergo the decarboxylative arylation upon treatment with aryl bromides, $\mathrm{Pd}\left(\mathrm{acac}_{-} \mathrm{F}_{6}\right)_{2}(1 \mathrm{~mol} \%$, acac $=$ 1,1,1,5,5,5-hexafluoroacetylacetonate), $\mathrm{CuBr}$ (15 mol\%), $\mathrm{P}(o \text {-tolyl })_{3}(2 \mathrm{~mol} \%)$, and 1,10-phenanthroline (15 $\mathrm{mol} \%$ ) in NMP/quinoline at $170^{\circ} \mathrm{C}$ for $16 \mathrm{~h}$ to form the corresponding aryl ketones (Scheme 52). ${ }^{85}$

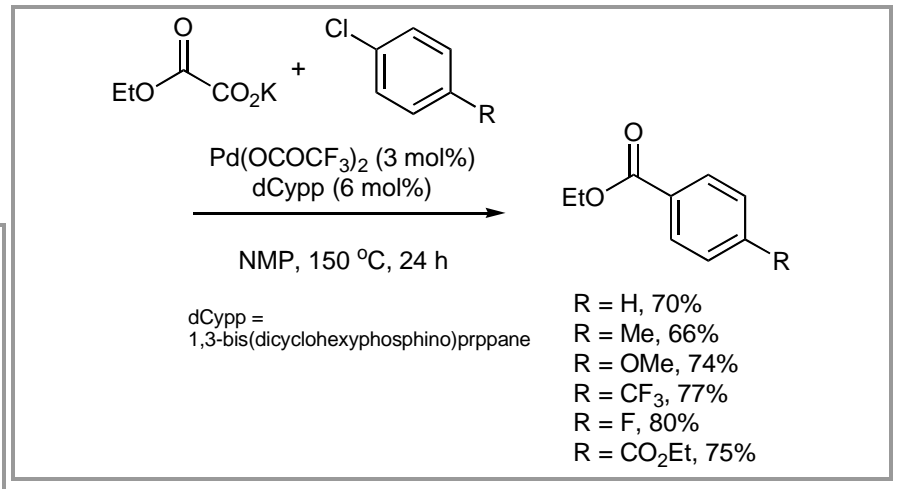

Scheme 53

\section{5 ipso-Vinylation}

In 2002, Myers and co-workers disclosed the first effective example of catalytic decarboxylative MizorokiHeck-type coupling. ${ }^{87-89}$ For example, treatment of ortho-substituted benzoic acids with styrene in the presence of $\mathrm{Pd}\left(\mathrm{OCOCF}_{3}\right)_{2}(20 \mathrm{~mol} \%)$ and $\mathrm{Ag}_{2} \mathrm{CO}_{3}$ (3 equiv) in DMF/DMSO at $80-120{ }^{\circ} \mathrm{C}$ produces the corresponding stilbenes selectively (Scheme 54).

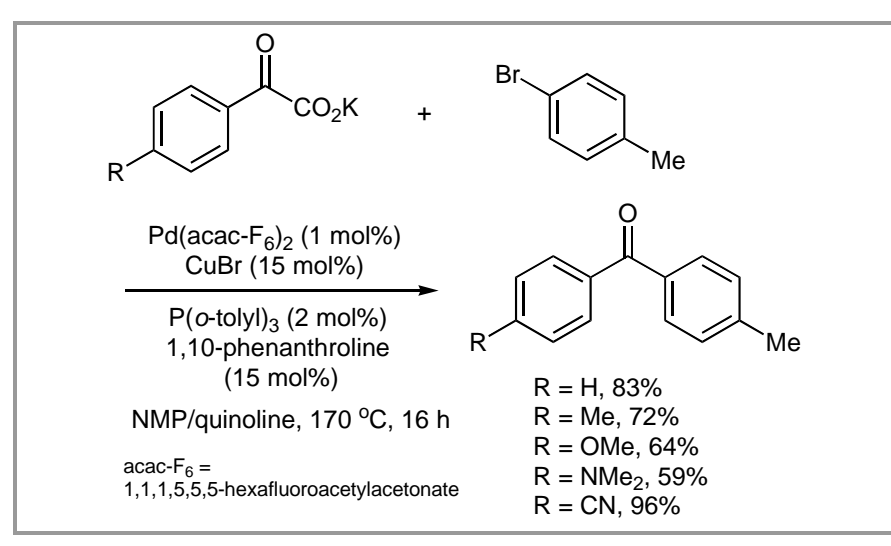

Scheme 52

Aromatic esters can also be synthesized by the decarboxylative arylation of potassium oxalate monoesters with aryl bromides and chlorides, as reported by Fu, Liu, and co-workers (Scheme 53). ${ }^{86}$ The catalyst system of $\mathrm{Pd}\left(\mathrm{OCOCF}_{3}\right)_{2}(3 \mathrm{~mol} \%)$ and dCypp $(6 \mathrm{~mol} \%, \mathrm{dCypp}=$ 1,3-bis(dicyclohexylphosphino)propane) is effective for the reaction.

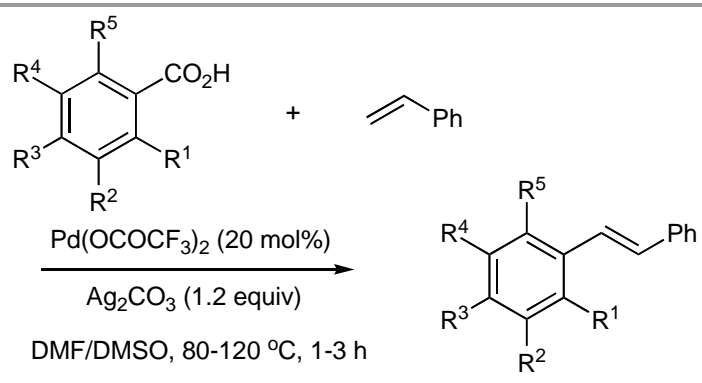

$R^{1}=R^{3}=R^{4}=$ OMe $; R^{2}=R^{5}=H, 91 \%$ $R^{1}=R^{4}=$ OMe; $R^{2}=R^{3}=R^{5}=H, 71 \%$ $R^{1}=R^{5}=$ OMe; $R^{2}=R^{3}=R^{4}=H, 92 \%$ $R^{1}=O M e ; R^{2}=R^{3}=R^{4}=R^{5}=H, 72 \%$ $\mathrm{R}^{1}=\mathrm{R}^{3}=\mathrm{R}^{5}=\mathrm{Me} ; \mathrm{R}^{2}=\mathrm{R}^{4}=\mathrm{H}, 99 \%$ $R^{1}=R^{5}=O M e ; R^{2}=B r ; R^{3}=R^{4}=H, 82 \%$ $R^{3}=R^{4}=O M e ; R^{1}=N_{2} ; R^{2}=R^{5}=H, 85 \%$

Scheme 54

A plausible mechanism for the palladium-catalyzed ipsovinylation of an ortho-substituted benzoic acid is illustrated in Scheme 55. The reaction seems to proceed via coordination of the carboxylate oxygen to an electrondeficient $\mathrm{PdX}_{2}$ species, decarboxylation, alkene insertion, and $\beta$-hydride elimination. 


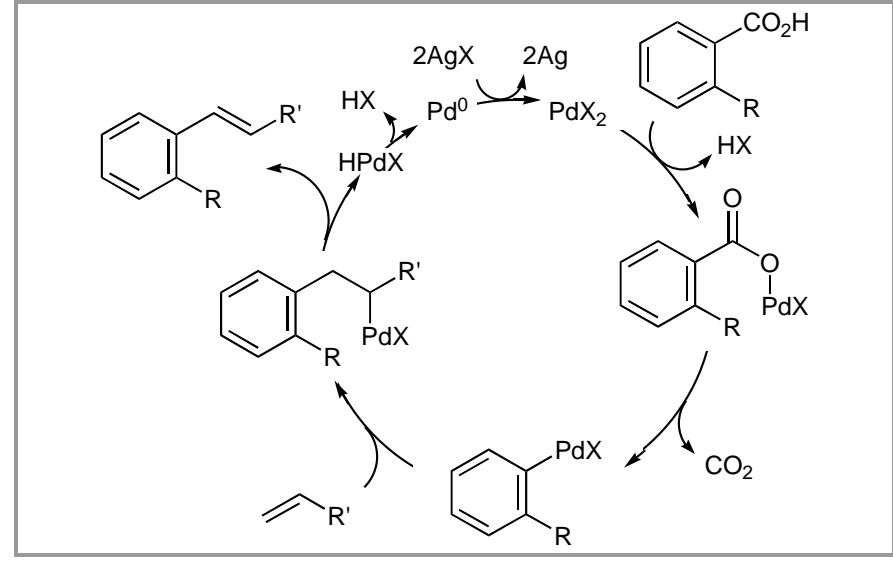

Scheme 55

With benzoic acids having no ortho-substitutent, not ipso-but ortho-vinylation takes place. The theoretical study by $\mathrm{Fu}$, Liu, and co-workers indicates that electrondonating substituents at the ortho-positions promote the rate-determining decarboxylation step effectively. ${ }^{90}$

Recently, Su and co-workers reported that a less expensive oxidant, benzoquinone, can also be employed in place of the silver salt for the decarboxylative vinylation. ${ }^{91}$

The decarboxylative vinylation of $o$-fluorinated benzoic acids can be conducted by using a $\mathrm{Rh}^{\mathrm{I}}$-catalyst, as reported by Zhao and co-workers (Scheme 56) ${ }^{92,93}$ In this reaction, small amounts of conjugate addition products are also formed.

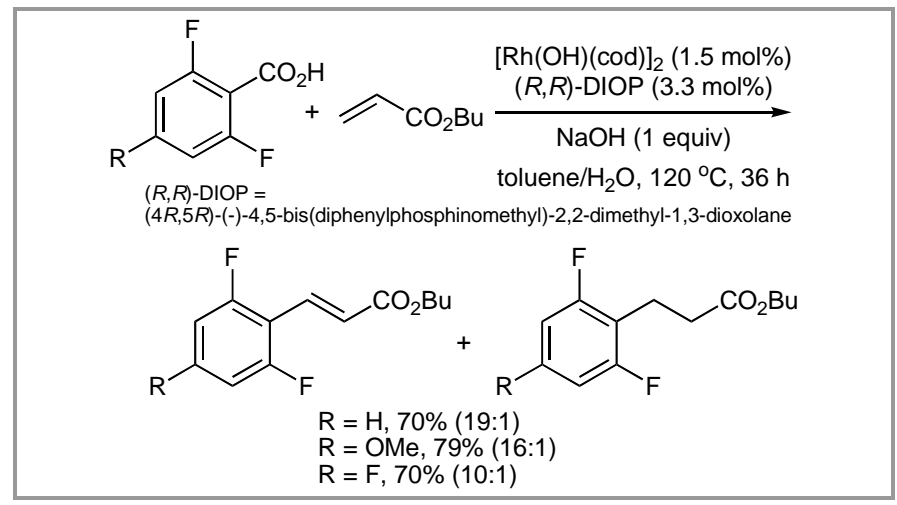

Scheme 56

Electron-rich cinnamic acids such as ferulic acid undergo the decarboxylative vinylation upon treatment with bromostyrenes in the presence of $\mathrm{Pd}(\mathrm{OAc})_{2}(3 \mathrm{~mol} \%)$, $\mathrm{LiOAc}$ (2 equiv), and $\mathrm{LiCl}$ (1.5 equiv) in $\mathrm{DMF}$ at $120^{\circ} \mathrm{C}$ for $6 \mathrm{~h}$ to produce the corresponding 1,4-diaryl-1,3butadiene derivatives (Scheme 57). ${ }^{94}$ 5-Phenyl-2,4pentadienoic acid also couples with the bromides efficiently to afford 1,6-diaryl-1,3,5-hexatrienes. Such $\alpha, \omega$ diarylated butadiene and hexatriene derivatives are highly important for their application to liquid crystals, illuminants, and nonlinear optical materials. ${ }^{95}$

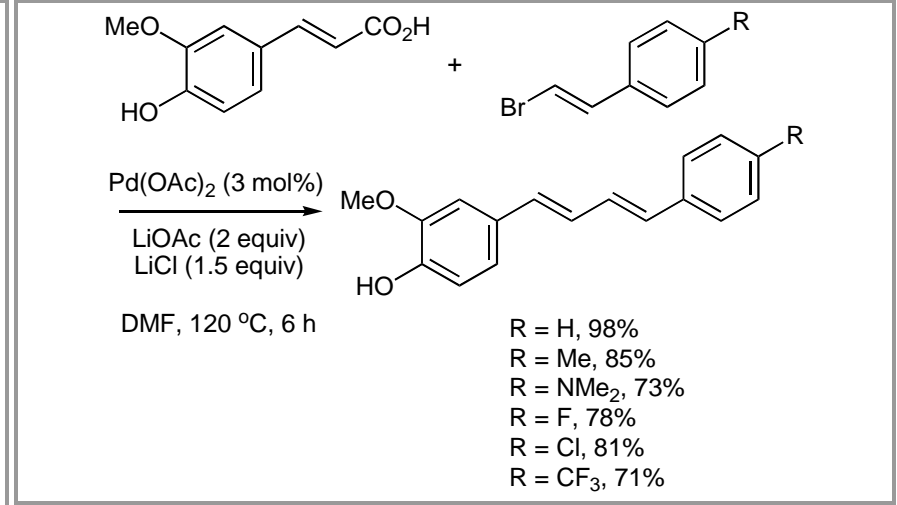

Scheme 57

\section{Conclusions}

The transition-metal-catalyzed arylation and vinylation at the ortho- (cine-) and the ipso-positions of carboxylic acids, in which the carboxylic function acts as directing group and leaving group, respectively, have been significantly developed in recent years. Since a wide range of the substrates are readily available, these reactions can be useful tools in organic synthesis. Further effort will be made continuously to improve catalytic efficiency under milder conditions and to develop new types of coupling.

\section{References}

(1) (a) Colby, D. A.; Bergman, R. G.; Ellman, J. A. Chem. Rev 2010, 110, 624. (b) Sun, C.-L.; Li, B.-J.; Shi, Z.-J. Chem. Commun. 2010, 46, 677. (c) Ackermann, L.; Vicente, R.; Kapdi, A. R. Angew. Chem., Int. Ed. 2009, 48, 9792. (d) Chen, X.; Engle, K. M.; Wang, D.-H.; Yu, J.-Q. Angew. Chem., Int. Ed. 2009, 48, 5094. (e) Kakiuchi, F.; Kochi, T. Synthesis 2008, 3013. (f) Ferreira, E. M.; Zhang, H.; Stoltz, B. M. Tetrahedron 2008, 64, 5987. (g) Park, Y. J.; Park, J.W.; Jun, C.-H. Acc. Chem. Res. 2008, 41, 222. (h) Herrerias, C. I.; Yao, X.; Li, Z.; Li, C.-J. Chem. Rev. 2007, 107, 2546. (i) Alberico, D.; Scott, M. E.; Lautens, M. Chem. Rev. 2007, 107, 174. (j) Godula, K.; Sames, D. Science 2006, 312, 67. (k) Satoh, T.; Miura, M. J. Synth. Org. Chem. 2006, 64, 1199. (1) Conley, B. L.; Tenn, W. J., III; Young, K. J. H.; Ganesh, S. K.; Meier, S. K.; Ziatdinov, V. R.; Mironov, O.; Oxgaard, J; Gonzales, J.; Goddard, W. A., III; Periana, R. A. J. Mol. Catal. A 2006, 251, 8. (m) Kakiuchi, F.; Chatani, N. Adv. Synth. Catal. 2003, 345, 1077. (n) Ritleng, V.; Sirlin, C.; Pfeffer, M. Chem. Rev. 2002, 102, 1731. (o) Kakiuchi, F.; Murai, S. Acc. Chem. Res. 2002, 35, 826. (p) Dyker, G. Angew. Chem., Int. Ed. 1999, 38, 1698. (q) Shilov, A. E.; Shul'pin, G. B. Chem. Rev. 1997, 97, 2879.

(2) (a) Yorimitsu, H.; Oshima, K. Bull. Chem. Soc. Jpn. 2009, 82, 778. (b) Park, Y. J.; Park, J.-W.; Jun, C.-H. Acc. Chem. Res. 2008, 41, 222. (c) Catellani, M.; Motti, E.; Della Ca', N. Acc. Chem. Res. 2008, 41, 1512. (d) Nakao, Y.; Hiyama, T. Pure Appl. Chem. 2008, 80, 1097. (e) Tobisu, M.; Chatani, N. Chem. Soc. Rev. 2008, 37, 300. (f) Satoh, T.; Miura, M. Top Organomet. Chem. 2007, 24, 61. (g) Murakami, M.; Makino, M.; Ashida, S.; Matsuda, T. Bull. Chem. Soc. Jpn. 2006, 79, 1315. (h) Kondo, T.; Mitsudo, T. Chem. Lett. 2005, 34, 1462. (i) Satoh, T.; Miura, M. Top. Organomet. Chem. 2005, 14, 1. (j) Jun, C.-H. Chem. Soc. Rev. 2004, 33, 610. (k) Nishimura, T.; Uemura, S. Synlett 2004, 201. (1) van der Boom, M. E.; Milstein, D. Chem. Rev. 2003, 103, 1759. (m) Catellani, M. Synlett 2003, 298. (n) 
Perthuisot, C.; Edelbach, B. L.; Zubris, D. L.; Simhai, N.; Iverson, C. N.; Muller, C.; Satoh, T.; Jones, W. D. J. Mol. Catal. A: Chem. 2002, 189, 157. (o) Mitsudo, T.; Kondo, T. Synlett 2001, 309. (p) Rybtchinski, B.; Milstein, D. Angew. Chem., Int. Ed. 1999, 38, 870. (q) Murakami, M.; Ito, Y. Top. Organomet. Chem. 1999, 3, 97. (r) Crabtree, R. H. Chem. Rev. 1985, 85, 245.

(3) Murai, S.; Kakiuchi, F.; Sekine, S.; Tanaka, Y.; Kamatani, A.; Sonoda, M.; Chatani, N. Nature 1993, 366, 529.

(4) Terao, Y.; Wakui, H.; Satoh, T.; Miura, M.; Nomura, M. J. Am. Chem. Soc. 2001, 123, 10407.

(5) Terao, Y.; Wakui, H.; Nomoto, N.; Satoh, T.; Miura, M.; Nomura, M. J. Org. Chem. 2003, 68, 5236.

(6) Yokooji, A.; Satoh, T.; Miura, M.; Nomura, M. Tetrahedron 2004, 60, 6757 .

(7) Nakano, M.; Satoh, T.; Miura, M. J. Org. Chem. 2006, 71, 8309.

(8) Maehara, A.; Satoh, T.; Miura, M. Tetrahedron 2008, 64, 5982.

(9) Nishimura, T.; Araki, H.; Maeda, Y.; Uemura, S. Org. Lett. 2003, 5, 2997.

(10) Funayama, A.; Satoh, T.; Miura, M. J. Am. Chem. Soc. 2005, 127, 15354.

(11) Satoh, T.; Tsurugi, H.; Miura, M. Chem. Rec. 2008, 8, 326.

(12) Kisenyi, J. M.; Sunley, G. J.; Cabeza, J. A.; Smith, A. J.; Adams, H.; Salt, N. J.; Maitlis, P. M. J. Chem. Soc., Dalton Trans. 1987, 2459.

(13) Kanaya, S.; Komine, N.; Hirano, M.; Komiya, S. Chem. Lett. 2001, 1284.

(14) Larock, R. C.; Varaprath, S.; Lau, H. H.; Fellows, C. A. J. Am. Chem. Soc. 1984, 106, 5274.

(15) Miura, M.; Tsuda, T.; Satoh, T.; Pivsa-Art, S.; Nomura, M. J. Org. Chem. 1998, 63, 5211 .

(16) Goossen, L. J.; Rodriguez, N.; Goossen, K. Angew. Chem., Int. Ed. 2008, 47, 3100.

(17) Baudoin, O. Angew. Chem., Int. Ed. 2007, 46, 1373.

(18) Giri, R.; Maugel, N.; Li, J.-J.; Wang, D.-H.; Breazzano, S. P.; Saunders, L. B.; Yu, J.-Q. J. Am. Chem. Soc. 2007, 129, 3510.

(19) Wang, D.-H.; Mei, T.-S. Yu, J.-Q. J. Am. Chem. Soc. 2008, $130,17676$.

(20) Chiong, H. A.; Pham, Q.-N.; Daugulis, O. J. Am. Chem. Soc. 2007, 129, 9879 .

(21) Nakano, M.; Tsurugi, H.; Satoh, T.; Miura, M. Org. Lett. 2008, 10,1851 .

(22) (a) Roger, J.; Gottumukkala, A. L.; Doucet, H. ChemCatChem 2010, 2, 20. (b) McGlacken, G. P.; Bateman, L. M. Chem. Soc. Rev. 2009, 38, 2447. (c) Bellina, F.; Rossi, R. Tetrahedron 2009, 65, 10269. (d) Liégault, B.; Lapointe, D.; Caron, L.; Vlassova, A.; Fagnou, K. J. Org. Chem. 2009, 74, 1826. (b) Mori, A.; Sugie, A. Bull. Chem. Soc. Jpn. 2008, 81, 548. (c) Seregin, I. V.; Gevorgyan, V. Chem. Soc. Rev. 2007, 36, 1173. (d) Satoh, T.; Miura, M. Chem. Lett. 2007, 36, 200.

(23) Miyasaka, M.; Fukushima, A.; Satoh, T.; Hirano, K.; Miura, M. Chem. Eur. J. 2009, 15, 3674.

(24) Ueura, K.; Satoh, T.; Miura, M. Org. Lett. 2007, 9, 1407.

(25) Ueura, K.; Satoh, T.; Miura, M. J. Org. Chem. 2007, 72, 5362.

(26) Satoh, T.; Ueura, K.; Miura, M. Pure Appl. Chem. 2008, 80, 1127.

(27) Maehara, A.; Tsurugi, H.; Satoh, T.; Miura, M. Org. Lett. 2008, 10, 1159 .

(28) Lu, P.; Sanchez, C.; Cornella, J.; Larrosa, I. Org. Lett. 2009, 11,5710 .

(29) Cornella, J.; Sanchez, C.; Banawa, D.; Larrosa, I. Chem. Commun. 2009, 7176.

(30) Gooßen, L. J.; Linder, C.; Rodríguez, N.; Lange, P. P.; Fromm, A. Chem. Commun. 2009, 7173.
(31) Gooßen, L. J.; Thiel, W. R.; Rodríguez, N.; Linder, C.; Melzer, B. Adv. Synth. Catal. 2007, 349, 2241.

(32) Dickstein, J. S.; Mulrooney, C. A.; O’Brien, E. M.; Morgan, B. J.; Kozlowski, M. C. Org. Lett. 2007, 9, 2441.

(33) Goossen, L. J.; Rodríguez, N.; Melzer, B.; Linder, C.; Deng, G.; Levy, L. M. J. Am. Chem. Soc. 2007, 129, 4824.

(34) Gooßen, L. J.; Deng, G.; Levy, L. M. Science 2006, 313, 662.

(35) (a) Jia, C.; Kitamura, T.; Fujiwara, Y. Acc. Chem. Res. 2001, 34, 633. (bas) Beccalli, E. M.; Broggini, G.; Martinelli, M.; Sottocornola, S. Chem. Rev. 2007, 107, 5318. (cb) Tsuji, J. Palladium Reagents and Catalysts, $2^{\text {nd }}$ ed.; John Wiley \& Sons: Chichester, UK, 2004.

(36) Grimster, N. P.; Gauntlett, C.; Godfrey, C. R. A.; Gaunt, M. J. Angew. Chem. Int. Ed. 2005, 44, 3125.

(37) Beck, E. M.; Grimster, N. P.; Hatley, R.; Gaunt, M. J. J. Am. Chem. Soc. 2006, 128, 2528.

(38) Wang, D.-H.; Engle, K. M.; Shi, B.-F.; Yu, J.-Q. Science 2010, 327, 315.

(39) Shi, B.-F.; Zhang, Y.-H.; Lam, J.-K.; Wang, D.-H.; Yu, J.-Q. J. Am. Chem. Soc. 2010, 132, 460.

(40) Shimizu, M.; Hirano, K.; Satoh, T.; Miura, M. J. Org. Chem. 2009, 74, 3478.

(41) Yamashita, M.; Hirano, K.; Satoh, T.; Miura, M. Org. Lett. 2009, 11, 2337.

(42) Yamashita, M.; Horiguchi, H.; Hirano, K.; Satoh, T.; Miura, M. J. Org. Chem. 2009, 74, 7481.

(43) Rossi, R.; Carpita, A.; Bellina, F.; Stabile, P.; Mannina, L. Tetrahedron 2003, 59, 2067.

(44) Nozawa, K.; Yamada, M.; Tsuda, Y.; Kawai, K.-I.; Nakajima, S. Chem. Pharm. Bull. 1981, 29, 2689.

(45) Nakajima, S.; Kawai, K.-I.; Yamada, S.; Sawai, Y. Agr. Biol. Chem. 1976, 40, 811 .

(46) Okazaki, M.; Yagi, N.; Wakizaka, Y. Yuki Gosei Kagaku Kyokaishi 1968, 26, 155.

(47) Nitta, K.; Yamamoto, Y.; Inoue, T.; Hyodo, T. Chem. Pharm. Bull. 1966, 14, 363.

(48) Mochida, S.; Hirano, K.; Satoh, T.; Miura, M. J. Org. Chem. 2009, 74, 6295.

(49) de Meijere, A.; Diederich, F.; Eds. Metal-catalyzed CrossCoupling Reactions: Wiley-VCH, Weinheim, 2004.

(50) Okazawa, T.; Satoh, T.; Miura, M.; Nomura, M. J. Am. Chem. Soc. 2002, 124, 5286.

(51) Miyasaka, M.; Hirano, K.; Satoh, T.; Miura, M. Adv. Synth. Catal. 2009, 351, 2683.

(52) Peschko, C.; Winklhofer, C.; Steglich, W. Chem. Eur. J. 2000, 6, 1147 .

(53) Forgione, P.; Brochu, M.-C.; St-Onge, M.; Thesen, K. H.; Bailey, M. D.; Bilodeau, F. J. Am. Chem. Soc. 2006, 128, 11350.

(54) Bilodeau, F.; Brochu, M.-C.; Guimond, N.; Thesen, K. H.; Forgione, P.; J. Org. Chem. 2010, 75, 1550.

(55) Gooßen, L. J.; Deng, G.; Levy, L. M. Science 2006, 313, 662.

(56) Goossen, L. J.; Rodríguez, N.; Melzer, B.; Linder, C.; Deng, G.; Levy, L. M. J. Am. Chem. Soc. 2007, 129, 4824

(57) Becht, J.-M.; Catala, C.; Le Drian, C.; Wagner, A. Org. Lett. 2007, 9, 1781.

(58) Becht, J.-M.; Le Drian, C. Org. Lett. 2008, 10, 3161.

(59) Shang, R.; Fu, Y.; Wang, Y.; Xu, Q.; Yu, H.-Z.; Liu, L. Angew. Chem. Int. Ed. 2009, 48, 9350.

(60) Goossen, L. J.; Zimmermann, B.; Knauber, T. Angew. Chem., Int. Ed. 2008, 47, 7103 .

(61) Arroyave, F. A.; Reynolds, J. R. Org. Lett. 2010, 12, 1328.

(62) Goossen, L. J.; Rodriguez, N.; Linder, C. J. Am. Chem. Soc. 2008, 130, 15248 .

(63) Goossen, L. J.; Linder, C.; Rodriguez, N.; Lange, P. P. Chem. Eur. J. 2009, 15, 9336. 
(64) Goossen, L. J.; Lange, P. P.; Rodriguez, N.; Linder, C. Chem. Eur. J. 2010, 16, 3906.

(65) Goossen, L. J.; Rodriguez, N.; Lange, P. P.; Linder, C. Angew. Chem., Int. Ed. 2010, 49, 1111.

(66) Voutchkova, A.; Coplin, A.; Leadbeater, N. E.; Crabtree, R. H. Chem. Commun. 2008, 6312.

(67) Yu, W.-Y.; Sit, W. N.; Zhou, Z.; Chan, A. S.-C. Org. Lett. 2009, 11, 3174 .

(68) Cornella, J.; Lu, P.; Larrosa, I. Org. Lett. 2009, 11, 5506.

(69) Xie, K.; Yang, Z.; Zhou, X.; Li, X.; Wang, S.; Tan, Z.; An, X.; Guo, C.-C. Org. Lett. 2010, 12, 1564.

(70) Wang, C.; Piel, I.; Glorius, F. J. Am. Chem. Soc. 2009, 131, 4194.

(71) Wang, Z.; Ding, Q.; He, X.; Wu, J. Org. Biomol. Chem. 2009, 7, 863 .

(72) Yamashita, M.; Hirano, K.; Satoh, T.; Miura, M. Chem. Lett. 2010, 39, 68.

(73) Iriti, M.; Faoro, F. Med. Hypotheses 2006, 67, 833.

(74) Heynekamp, J. J.; Weber, W. M.; Hunsaker, L. A.; Gonzales, A. M.; Orland, R. A.; Deck, L. M.; Vander Jagt, D. L. J. Med. Chem. 2006, 49, 7182.

(75) Vessières, A.; Top, S.; Pigeon, P.; Hillard, E.; Boubeker, L.; Spera, D.; Jaouen, G. J. Med. Chem. 2005, 48, 3937.

(76) Grimsdale, A. C.; Chan, K. L.; Martin, R. E.; Jokisz, P. G.; Holmes, A. B. Chem. Rev. 2009, 109, 897.

(77) Kraft, A.; Grimsdale, A. C.; Holmes, A. B. Angew. Chem., Int. Ed. 1998, 37, 402.

(78) Marder, S. R.; Kippelen, B.; Jen, A. K.-Y.; Peyghambarian, N. Nature, 1997, 388, 845.

(79) Tsujiyama, S.; Ueno, M. Biosci. Biotechnol. Biochem. 2008, $72,212$.

(80) Nomura, E.; Hosoda, A.; Mori, H.; Taniguchi, H. Green Chem. 2005, 7, 863.

(81) Nomura, E.; Kashiwada, A.; Hosoda, A.; Nakamura, K.; Morishita, H.; Tsuno, T.; Taniguchi, H. Bioorg. Med. Chem. 2003, 11, 3807.

(82) Moon, J.; Jeong, M.; Nam, H.; Ju, J.; Moon, J. H.; Jung, H. M.; Lee, S. Org. Lett. 2008, 10, 945.

(83) Moon, J.; Jang, M.; Lee, S. J. Org. Chem. 2009, 74, 1403.

(84) Kim, H.; Lee, P. H. Adv. Synth. Catal. 2009, 351, 2827.

(85) Goossen, L. J.; Rudolphi, F.; Oppel, C.; Rodriguez, N. Angew. Chem., Int. Ed. 2008, 47, 3043.

(86) Shang, R.; Fu, Y.; Li, J.-B.; Zhang, S.-L.; Guo, Q.-X.; Liu, L. J. Am. Chem. Soc. 2009, 131, 5738.

(87) Myers, A. G.; Tanaka, D.; Mannion, M. R. J. Am. Chem. Soc. 2002, 124, 11250

(88) Tanaka, D.; Myers, A. G. Org. Lett. 2004, 6, 433.

(89) Tanaka, D.; Romeril, S. P.; Myers, A. G. J. Am. Chem. Soc. 2005, 127, 10323.

(90) Zhang, S.-L.; Fu, Y.; Shang, J.-B.; Guo, Q.-X.; Liu, L. J. Am. Chem. Soc. 2010, 132, 638.

(91) Hu, P.; Kan, J.; Su, W.; Hong, M. Org. Lett. 2009, 11, 2341.

(92) Sun, Z.-M.; Zhang, J.; Zhao, P. Org. Lett. 2010, 12, 992.

(93) Sun, Z.-M.; Zhao, P. Angew. Chem., Int. Ed. 2009, 48, 6726.

(94) Yamashita, M.; Hirano, K.; Satoh, T.; Miura, M. Org. Lett. 2010, 12, 592.

(95) (a) Davis, R.; Kumar, N. S. S.; Abraham, S.; Suresh, C. H.; Rath, N. P.; Tamaoki, N.; Das, S. J. Phys. Chem. C 2008, 112, 2137. (b) Sonoda, Y.; Goto, M.; Tsuzuki, S.; Tamaoki, N. J. Phys. Chem. A 2007, 111, 13441. (c) Sonoda, Y.; Goto, M.; Tsuzuki, S.; Tamaoki, N. J. Phys. Chem. A 2006, 110, 13379. (d) Abraham, S.; Mallia, V. A.; Ratheesh, V.; Tamaoki, N.; Das, S. J. Am. Chem. Soc. 2006, 128, 7692. (e) Lightfoot, A. P.; Twiddle, S. J. R.; Whiting, A. Org. Biomol. Chem. 2005, 3, 3167. (f) Denmark, S. E.; Tymonko, S. A. J. Am. Chem. Soc. 2005, 127, 8004. (g) Davis, R.; Mallia, V. A.; Das, S.; Tamaoki, N. Adv. Funct. Mater. 2004, 14, 743. (h) Davis, R.; Abraham, S.; Rath, N. P.; Das, S. New J. Chem. 2004, 28, 1368. (i) Sonoda, Y.; Kawanishi,
Y.; Ikeda, T.; Goto, M.; Hayashi, S.; Yoshida, Y.; Tanigaki, N.; Yase, K. J. Phys. Chem. B 2003, 107, 3376. (j) Davis, R.; Mallia, V. A.; Das, S. Chem. Mater. 2003, 15, 1057. (k) Bartkowiak, W.; Zalesny, R.; Niewodniczanski, W.; Leszczynski, J. J. Phys. Chem. A 2001, 105, 10702. (1) Locknar, S. A.; Peteanu, L. A.; Shuai, Z. J. Phys. Chem. A 1999, 103, 2197. (m) Andraud, C.; Zabulon, T.; Collet, A.; Zyss, J. Chem. Phys. 1999, 245, 243. (n) Crousse, B.; Alami, M.; Linstrumelle, G. Tetrahedron Lett. 1997, 38, 5297. (o) Cheng, L.-T.; Tam, W.; Marder, S. R.; Stiegman, A. E.; Rikken, G.; Spangler, C. W. J. Phys. Chem. 1991, 95, 10643. (p) Allen, M. T.; Whitten, D. G. Chem. Rev. 1989, 89,1691 